\title{
Revolutionising Cost Structure for Integrated Project Delivery: A BIM-Based Solution
}

Faris Ali Khairy Elghaish, Sepehr Abrishami, M.Reza Hosseini \& Soliman Abu-Samra

\section{ABSTRACT:}

\section{Purpose}

The amalgamation of Integrated Project Delivery (IPD) and Building Information Modelling (BIM) is highly recommended for successful project delivery. However, IPD lacks an accurate cost estimation methodology at the 'front-end' of projects, when little project information is available. The current study tackles this issue, through presenting analytical aspects, theoretical grounds, and practical steps/procedures for integrating Target Value Design (TVD), ActivityBased Costing (ABC), and Monte Carlo simulation into the IPD cost structure, within a BIMenabled platform.

\section{Design/methodology/approach}

A critical review was conducted to study the status of cost estimation within IPD, as well as, exploring methods and tools that can enhance the cost estimation process for IPD. Thereafter, a framework is developed to present the proposed methodology of cost estimation for IPD throughout its entire stages. A case project is used to validate the practicality of the developed solution through comparing the profit-at-risk percentage for each party, using both traditional cost estimation and the proposed solution.

\section{Findings}

After applying the proposed IPD's cost estimation framework, on a real-life case project, the findings demonstrated significant deviations in the profit-at-risk value for various work packages of the project (approximately 100\% of the finishing package and 22\% of openings package). By providing a precise allocation of overhead costs, the solution can be used in real- 


\section{This research is accepted to be published in ECAM journal DOI (10.1108/ECAM-04-2019-0222)}

life projects to change the entire IPD cost structure and ensure a fair sharing of risk-rewards amongst the involved parties in IPD projects.

\section{Practical implications}

Using the proposed methodology of cost estimation for IPD can enhance the relationship amongst IPD's core team members; all revealed financial deficiencies will be considered (i.e. compensation structure, profit pooling), hence, enhancing the IPD performance.

\section{Originality/value}

This paper presents a comprehensive solution for integrating BIM and IPD in terms of cost estimation, offering three main contributions: (1) an innovate approach to utilise 5D BIM capabilities with Monte Carlo simulation, hence providing reliable cost estimating during the conceptual TVD stage; (2) mathematical models that are developed through integrating ABC into the detailed 5D BIM to determine the three IPD's cost structure limbs; (3) a novel mechanism of managing cost saving (rewards) through distinguishing between saved resources from organisation level, to daily task level, to increase trust among parties.

Keywords: IPD, 5D BIM, collaboration, alliancing, simulation, procurement, partnering agreement.

\section{Introduction}

Integrated project deliyery (IPD) is characterised by the early, collaborative and collective engagement of key stakeholders through all phases of delivering a project (Ashcraft, 2014, Ahmad et al., 2019).Compared to common methods of project delivery like design-bid-build, construction management at-risk and design-build, IPD is providing a new procurement style to enhance performance (Asmar et al., 2016, Manata et al., 2018). Evidence shows that IPD can result in improving 14 metrics of project performance, including quality, scheduling, communication management and cost performance, among others (Asmar et al., 2016, Ahmad et al., 2019).

Traditional forms of IPD like alliancing and partnering agreement, can be implemented without BIM, these forms are characterised by early involvement of contractors, sharing risk/reward and the absence 


\section{This research is accepted to be published in ECAM journal DOI (10.1108/ECAM-04-2019-0222)}

of tender stage (Durdyev et al., 2019). New styles of IPD are, however, more collaborative in nature. These modern forms adopt the 'big room' concept, as a shared space where team members or representatives work (Merschbrock et al., 2018). Besides, with the growth of BIM, new forms of IPD are defined in integration with BIM, Information and Communication Technologies (ICT) and webbased management systems (Fischer et al., 2017, Rowlinson, 2017). The new forms target smoothing data exchange among project's packages and parties, (Niemann, 2017, AIA, 2007, Elghaish et al., 2019b). New forms of IPD, in integration with BIM, improve a wide range of likely outcomes of design and construction including cost/profit, scheduling, return on investment (RoI), safety, productivity and relationships (Ilozor and Kelly, 2012, Azhar et al., 2015).

Integrated project delivery (IPD) relies on open pricing techniques and fiscal transparency among participants (Ahmad et al., 2019, Elghaish et al., 2019c). In addition, project stakeholders, such as designers and contractors, typically assess and determine their profit and shared risks, according to the deviation between actual and target costs (AIA, 2007). Cost estimation is essential for the compensation arrangement, which defines accurate risk/reward proportions (Love et al., 2011). Hence, accurate cost estimation is vital for the successful delivery of the IPD-based projects (Allison et al., 2017, AIA, 2007, Ebrahimi and Dowlatabadi, 2018). Target value design (TVD) is treated as part of the IPD approach, with TVD requiring rapid cycles of suggestions and analyses of costs (Alves et al., 2017). Therefore, continuous estimation feedback is essential for accomplishing the preconstruction IPD stages and making informed decisions (Allison et al., 2017, Zimina et al., 2012). With these facts in mind, a precise semi-automated, agile estimation technique that is interoperable with BIM data is deemed an ideal solution (Pishdad-Bozorgi et al., 2013).

Cost estimation practices in IPD are not yet well established (Chen et al., 2012). This warrants expansion of the capacity of BIM in the form of an innovative cost estimation solution to support the TVD process (Pishdad-Bozorgi et al., 2013, Hall et al., 2018, Alves et al., 2017), with this being the primary objective of this study.

This study contributes to the field by addressing the need for a TVD-based solution for IPD, based on BIM's capabilities. In broader terms, the study provides a background for addressing the need for 


\section{This research is accepted to be published in ECAM journal DOI (10.1108/ECAM-04-2019-0222)}

accurate cost estimation at planning stages of IPD projects, for which little research currently exists (Andersen et al., 2016, Welde and Odeck, 2017). To make the findings appealing to the world of practice, the practicality and potential advantages of the proposed solution are evaluated in a case project, by comparing its performance against that of common traditional methods.

\section{Background}

\section{Cost estimation of construction projects}

Meeting the planned cost metrics, although frequently criticised, is still considered the gold standard for measuring project success (Berssaneti and Carvalho, 2015, Kim et al., 2004). Thus, cost estimation is an important element of project planning (Torp and Klakegg, 2016). According to the Project Management Institute (PMI (2017), cost estimation is the iterative process of estimating project resources, required for project activities; therefore, linking resources and activities is vital for successful cost estimation. Major cost estimation activities must typically occur early in a project, when minimal project information is available (Kim et al., 2004, Welde and Odeck, 2017). Therefore, uncertainty remains a major cause of poor costestimation across the construction industry (Johansen et al., 2014, Torp and Klakegg, 2016, Andersen et al., 2016). Uncertainty is identified as "controllable and non-controllable factors that may occur, and variation and foreseeable events that occur during a project execution, and that has a significant impact on the project objective." (Johansen et al., 2014)

The greatest level of uncertainty for cost estimation purposes belongs to the feasibility study stages of projects, colloquially termed the 'front-end' of projects (Andersen et al., 2016, Welde and Odeck, 2017, Caffieri et al., 2018), where uncertainty levels ranging from $-30 \%$ to $+50 \%$ can be expected (Johansen et al., 2014).

In IPD, the overall risk is equal to that of traditional methods, and the owner must guarantee the direct cost of projects (Ghassemi and Becerik-Gerber, 2011). As a result, IPD relies heavily on cost estimation at the project feasibility study phase, to develop a reliable business case for decisionmaking purposes (Allison et al., 2017, Pishdad-Bozorgi et al., 2013).

\section{Cost estimation in integrated project delivery (IPD)}




\section{This research is accepted to be published in ECAM journal DOI (10.1108/ECAM-04-2019-0222)}

A major hallmark of IPD is its compensation system for allocating gain/pain ratios among project participants (Ashcraft, 2014, Fischer et al., 2017). This necessitates a cooperative contracting relationship that ties the individual success of participants to success - in achieving the project objectives (AIA, 2007, Ahmad et al., 2019, Pishdad-Bozorgi, 2017). All participants must agree upon a suitable compensation scheme (Pishdad-Bozorgi et al., 2013), with this scheme determining the proportions of cost overrun, cost underrun and any other fees in the total budget under the agreed cost (Pishdad-Bozorgi et al., 2013, Fischer et al., 2017). The cost scheme must comprise direct, indirect and overhead costs and capture the risk/reward proportions based on the degree of achievement during project delivery (Love et al., 2011, Pishdad-Bozorgi et al., 2013, Zhang and Li, 2014). In IPD, three components or limbs can be defined: Limb 1, representing the reimbursement of project costs, which captures all project implementation costs (guaranteed); Limb 2 represents the overhead costs for all participants in addition to the profit (at-risk); and Limb 3 is the pain or gain ratios (the contractual agreement) (Raisbeck et al., 2010, Zhang and Li, 2014, Elghaish et al., 2019a). Therefore, according to Das and Teng (2001), a precise determination of risk is critical; participants who are exposed to more uncertainty must be compensated for the risks against a higher profit-at-risk percentage. Target value design (TVD), as described next, is proven to offer a highly reliable route to successful project cost estimation for IPD arrangements (Zimina et al., 2012, Do et al., 2014).

\section{Target value design (TVD)}

Target value design (TVD), an emerging practice in the construction industry, is a management strategy that aims to eliminate waste and deliver value using a 'design-to-cost' method (Meijon Morêda Neto et al., 2019). The thrust of TVD is to position a client's value (e.g., cost, schedule, etc.) as the driver of design to reduce waste and satisfy the client's expectations (Zimina et al., 2012). Target value design (TVD) thus introduces a philosophy towards design based on budget, in contrast to the idea of budgeting for design - a traditional design concept - and, therefore, cost estimating becomes a crucial part of design development (Allison et al., 2017). Empirical research shows that TVD projects can achieve cost reductions of 15-20\% and contingency costs of approximately $3.5 \%$ compared to 7.9\% for non-TVD projects (Silveira and Alves, 2018, Meijon Morêda Neto et al., 2019). 


\section{This research is accepted to be published in ECAM journal DOI (10.1108/ECAM-04-2019-0222)}

Consequently, TVD is recommended as an effective solution for IPD projects (de Melo et al., 2016, Pishdad-Bozorgi et al., 2013). Successful TVD requires extensive collaboration among designers, builders, quantity surveyors and trade partners (Alwisy et al., 2018); all these parties must be at the table and offer continuous feedback to influence design and achieve owner's goals, while complying with the set budget, as argued by Pishdad-Bozorgi et al. (2013) and Allison et al. (2017). This collaboration is based on multiple interactions and rapid circles of suggestions, analysis and feedback to allow continuous improvements and to find the solutions that meet the client's - or multiple stakeholders' - definition of value (Alves et al., 2017, Silveira and Alves, 2018). Therefore, TVD is implemented with the support of lean management tools to facilitate effective collaboration and make possible these rapid circles of conceptualisation, analysis and estimation (Meijon Morêda Neto et al., 2019, Alwisy et al., 2018, Alves et al., 2017, Allison et al., 2017) Several of these - lean management - tools are described below.

\section{Five-dimensional (5D) Building Information Modelling (BIM)}

Building Information Modelling (BIM) is the primary tool, best suited to facilitate TVD for IPD projects (Alves et al., 2017, Pishdad-Bozorgi et al., 2013, Allison et al., 2017, Meijon Morêda Neto et al., 2019). This tool has the potential to enable a comprehensive and accurate design from early stages of a project (Nassar, 2012, Eastman et al., 2018, Lu et al., 2016). The five-dimensional cost model, termed ' $5 \mathrm{D}$ BIM,' is promoted as the preferred method for extracting quantities and cost estimations from 3D models (Zheng et al., 2019, Aibinu and Venkatesh, 2013, Nassar, 2012). Through BIM, the project team is proyided with an enhanced capability to take into account any changes in the design development process and the resultant impacts on the value (Lu et al., 2018, Nassar, 2012, Hannon, 2007, Zheng et al., 2019, Eastman et al., 2018, Rahimian et al., 2020). This involves developing a schematic BIM model to organise the schematic design and estimation of value, and linking this BIM model to various external databases to efficiently extract cost items (Lu et al., 2018, Rahimian et al., 2008). Other advantages of 5D BIM over traditional methods are also well documented: increased efficiency, improved visualisation of construction details and earlier risk identification (Stanley and 


\section{This research is accepted to be published in ECAM journal DOI (10.1108/ECAM-04-2019-0222)}

Thurnell, 2014a, Lu et al., 2016), thus enabling cost estimates to reach optimum solutions and reducing errors and misleading estimates (Shen and Issa, 2010).

\section{Integrating BIM, IPD and TVD: The benefits}

According to Alves et al. (2017), BIM is "an important part of the TVD process. BIM allows project participants to quickly develop solutions, visualise them in three- and four-dimensional (time added) environments, while also understanding the impact of their decisions on the cost of the project." And integrating IPD and BIM is necessary to maximises the full benefits of each one (Lancaster and Tobin, 2010, Durdyev et al., 2019). Given the affinity between TVD and IPD, as discussed, there is much potential for having 5D BIM and TVD for IPD project delivery (Zheng et al., 2019, Porwal and Hewage, 2013, Alves et al., 2017), as discussed below.

Zhang and Wang (2009) recommended IPD projects to use BIM technologies, to enable collaboration and sharing risk/reward among project participants. Through analysing the outcome of implementing BIM in 145 projects, Chang et al. (2017) asserted the ability of BIM to maximise the acceptability of IPD, particularly, through creating a flexible supply chain and improving communication quality among project participants. That is, implementing IPD requires a collaboration platform, effective communication, information sharing and negotiation (Ma and Ma, 2017). BIM can provide all such demands (Merschbrock et al., 2018, Pishdad-Bozorgi et al., 2013, Rowlinson, 2017, Ahmad et al., 2019).

Moving beyond BIM and IPD, the benefits of coupling of BIM, IPD and lean-based methods is recognised by researchers like Dossick et al. (2013), who supported that such integration enhances the quality of design and construction deliverables. Integrating IPD, BIM and other lean techniques such as Target Value Design (TVD) can result in noticeable improvements, in terms of project scheduling and cost reduction (Nguyen and Akhavian, 2019). Jang et al. (2019), similarly, assert the importance of implementing TVD with BIM and IPD, to enable subcontractors involvement in the design process, and therefore, complete designing according to the client's budget. 


\section{This research is accepted to be published in ECAM journal DOI (10.1108/ECAM-04-2019-0222)}

On the other hand, successful implementation of TVD and meet the set requirements for both schedule and cost relies on adopting IPD approach, to leverage the full potential of individuals in contributing to the design process (Laurent and Leicht, 2019, Ebrahimi and Dowlatabadi, 2018) and avoid the misalignments of commercial incentives among IPD team members (Do et al., 2015). This idea is however fraught with challenges, a description of which follows.

\section{Integrating BIM, IPD and TVD: The challenges}

Major challenges are lack of collaboration among various stakeholders like designers and quantity surveyors in developing 5D BIM models (Vigneault et al., 2019, Mayouf et al., 2019). Besides, as argued by Nassar (2011), linking cost estimation programs and BIM design platforms remains a challenge. And McCuen et al. (2011) claimed that the information extracted from a BIM model is not necessarily accurate. On the other hand, transferring data among various platforms causes waste and reduces accuracy (Azhar et al., 2012). Moreover, quantity surveyors are still responsible to articulate cost reports semi-manually: linking several models such as 3D design model, 5D platform to extract quantities and Excel sheet to determine prices, by exporting the derived quantities (Hudson-Smith, 2014). The integration between cost estimation and scheduling remains also a manual activity; this process is complicated and labour-intensive (Sunil et al., 2017). There is no single/dynamic platform to proceed the entire cost estimation, independent of other supporting tools (Cho et al., 2012).

There is no balance in the relationship between the amount of information required for cost estimation and the data added by the designers (Kiviniemi et al., 2007). Moreover, the pricing format is not considered in BIM models, but it is required by the quantity surveyors to modify the bill of quantity (BOQ) model, for each project in terms of their breakdown structure (Wu et al., 2014).

The lacuna is caused by the traditional soli-based approach, where each discipline uses a different model with limited regard for the cost estimating processes (Stanley and Thurnell, 2014b, Boon and Prigg, 2012). Consequently, project core team members usually waste many hours in adapting one model to meet the needs of cost estimation (Meadati, 2009). 


\section{This research is accepted to be published in ECAM journal DOI (10.1108/ECAM-04-2019-0222)}

In addition, all estimates and analysis related to IPD are fraught with uncertainty and unknown variables (Allison et al., 2017, Pishdad-Bozorgi et al., 2013). Using the single point estimates - out of the data provided by BIM - can result in extra levels of risks for IPD arrangements. There must be a shift from 'best and worst estimates,' to a range of outcomes; team members must use a distribution of unknown variables that control estimates, for which Monte Carlo can be a solution (Loizou and French, 2012).

\section{Capabilities of Monte Carlo Simulation}

Monte Carlo is a simulation method, capable of running a large number of trials to analyse the impact of risk and uncertainty of a probabilistic range of data, so that a probabilistic model can be built, taking into account unknown variables (Loizou and French, 2012, Alashwal and Chew, 2017). Monte Carlo simulation provides a range of values against specific degrees of uncertainty, offering great flexibility in the predictions of likely outcomes (Potts and Ankrah, 2014).

As for costs estimation prone to uncertainty, Monte Carlo has been described: as the most important statistical technique utilised for probabilistic cost estimations (Khedr, 2006); the most used technique in the literature for early cost estimation of construction projects (Alashwal and Chew, 2017); and one of the convenient methods available for property evaluation purposes (Jahangirian et al., 2010). There is no shortage of evidence in the literature that acknowledge the suitability of using Monte Carlo for cost estimation purposes. Zhu et al. (2016) assert that the Monte Carlo simulation is a proven tool to deal with the high level of uncertainty in the cost estimation with considering multiple variables. It is an effective tool for cost estimation of for specific products, at the early production stage (Li et al., 2014). The capabilities of Mont Carlo in cost estimation of probabilistic activities can be enhanced, in integration with Activity Based Costing (ABC) (Cassettari et al., 2016), a brief description of which follows.

\section{Activity-based costing (ABC)}

Traditional costing methods, termed resource-based costing (RBC), rely on the cost of the required resources (Kim and Ballard, 2001). With these methods, however, cost distortion occurs, as the methods combine and allocate all indirect costs to a single pool of costs, based on the resources 


\section{This research is accepted to be published in ECAM journal DOI (10.1108/ECAM-04-2019-0222)}

common to all products of an organisation (Kim et al., 2011, Wang et al., 2010). In other words, traditional methods fail to find key decision variables that affect the total cost, particularly overhead costs (Kim et al., 2016). Activity-based costing (ABC) prevents this distortion by allocating costs through multi-pools; this method determines overhead activities and costs needed to transform resources into activities that can deliver the final product (Kim and Ballard, 2001, Wang et al., 2010). The $\mathrm{ABC}$ approach can measure costs based on activities and link the cost drivers to the impact measures of a certain product or service (Tsai and Hung, 2009). The ABC method therefore can improve the efficiency and accuracy of cost-related information and further monitor and control project costs (Tsai et al., 2014). This becomes particularly relevant in a collaborative working environment - like IPD - in which multiple stakeholders, beyond the control of a single company, can affect cost drivers (Kim et al., 2016).

\section{Previous studies and gaps}

The review of the literature reveals that a major part of now-available research studies on the topic aims at informing practitioners of the potential of existing tools and techniques like TVD and BIM and describing how they contribute to the development of better IPD solutions. Pishdad-Bozorgi et al. (2013) discussed the potential of integration between TVD, BIM and IPD cost estimation, while Alves et al. (2017) presented various techniques commonly used for TVD and applicable to the IPD context. Zimina et al. (2012) and later de Melo et al. (2016) showed how systematic TVD can result in noticeable enhancement of project performance. Several studies have also mentioned the potential of BIM to add value to a project's objectives through IPD implementation (c.f.Ahmad et al., 2019, Chang et al., 2017, Succar, 2009, Fischer et al., 2017, Hosseini et al., 2018, Azhar et al., 2015).

Another stream of studies discusses the challenges and barriers of using TVD or BIM for IPD cost estimation tasks. For example, Ghassemi and Becerik-Gerber (2011), Manata et al. (2018), PishdadBozorgi (2017) and Kahvandi et al. (2018) focused on various key critical success factors, largely from a managerial perspective, with limited attention to cost estimation issues.

Tillmann et al. (2017) discussed the underlying mechanisms of TVD cost estimation within IPDoriented projects, exploring the factors that influence success when TVD is applied to these projects. 


\section{This research is accepted to be published in ECAM journal DOI (10.1108/ECAM-04-2019-0222)}

Despite their study's contributions, it does not focus on the tactics of allocating overhead resources. Earlier, Ballard et al. (2015) explored the relationship between IPD and TVD, and recommended a set of procedures to enhance the chance of success in applying TVD to IPD cost estimation processes. Although the authors acknowledged that following TVD principles is a critical success factor, no explicit technique or procedure was recommended to make the recommendations useful in practical terms. Roy et al. (2018a) identified the challenges and cost structure of implementing IPD: profit pooling, misunderstandings in risk contingency accounting and hard pricing are presented as critical barriers to IPD implementation. No workable solution was provided by these authors to address these challenges.

Some researchers have attempted to provide models and frameworks to address IPD cost estimation issues. As an example, Zhang and $\mathrm{Li}$ (2014) combined risk perception and Nash bargaining solution (NBS) techniques to formulate a risk-reward compensation model. However, the model was not sufficiently comprehensive to cover all possible types of engineering data, lacked empirical validity and, hence, required empirical studies. In addition, Pishdad-Bozorgi and Srivastava (2018) developed a model to share risks and rewards using a game theory approach, particularly for cases in which project cost exceed the profit-at-risk percentage. Their study only provided an overview of the model with future empirical research needed to assess its practicality and quantify its impacts.

In summary, the review of the literature reveals that integrating IPD, TVD and BIM is regarded as a winning combination for improving project delivery success (Pishdad-Bozorgi et al., 2013). However, limited research is available to validate the expected positive outcomes by providing workable solutions (Azhar et al., 2015, Kahvandi et al., 2017). The need to conduct the current study is thus acknowledged.

\section{Research methods}

The objective of the current study is to present a workable solution and explore its practicality in a reallife setting. This trial, in a real-life case, would be affected by many factors and mediated through various procedures. Context is hence an essential part of this study, that is, many variables from the 


\section{This research is accepted to be published in ECAM journal DOI}

(10.1108/ECAM-04-2019-0222)

setting can affect the outcome and interfere with the causes and effects of procedures. As argued by Yin (1981), exploratory case study is the most applicable method for conducting such context-dependent studies. In that sense case study is like simulation and experiment. The distinction is that case study tests a phenomenon in its real-life setting, where an experiment deliberately divorces a phenomenon from its context (Yin, 1981). Case study was thus selected as the primary method of this study, in testing the practicality of the solution in the construction context, the reason being: according to Fellows and Liu (2015), case study can be a suitable method for providing ideas and feedback about a construction management system. The illustrative case study is selected here to conduct the validation of the proposed solution due to it can bridge the gap between the researcher understanding and the target audience and inform potential users about a topic of which it was previously presented —or widely utilised (Fairley et al., 2005). The research design is illustrated in Figure 1.

\section{Research design and tools}

The study commences with a critical review of available IPD best practices, to identify any existing gap in the IPD cost structure. Given their recognised affinity (Ahmad et al., 2019), the correlation between BIM and IPD is examined. 
This research is accepted to be published in ECAM journal DOI

(10.1108/ECAM-04-2019-0222)

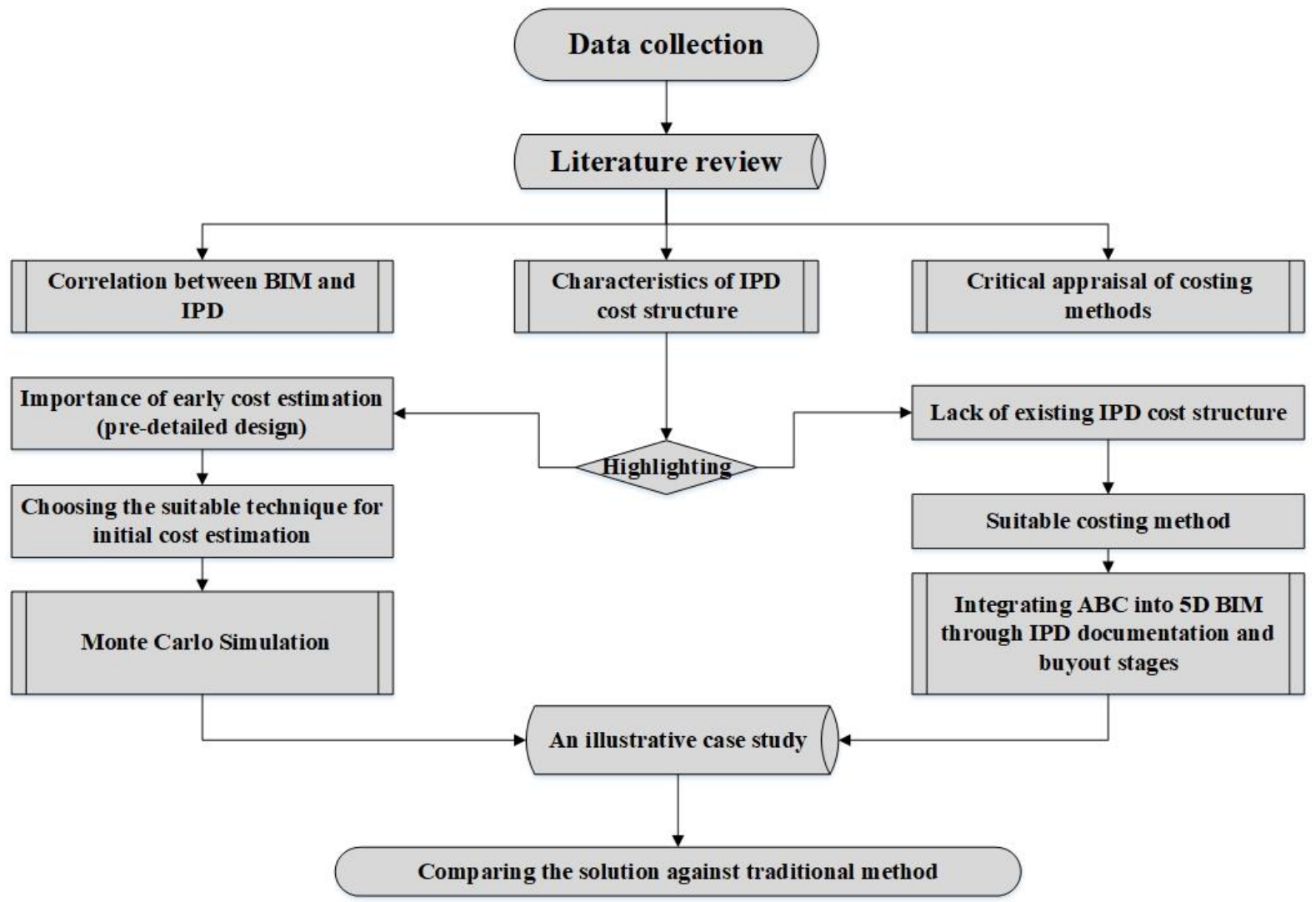

Figure 1. Research design

As discussed, integrating BIM tools into Monte Carlo Simulation can provide precise cost estimation throughout IPD pre-construction stages. This also supports parties involved in IPD in making informed decisions. To achieve the optimal IPD cost structure in the current study, $\mathrm{ABC}$ is used to appropriately allocate costs to each activity and justify that the right package price is obtained. The illustrative case study is next conducted to compare the case project results, using the traditional costing method - Resource Based Costing (RBC) - and the proposed framework - the solution - to highlight deviations (if any). This is to compare the two methods in terms of the monetary value of the profit-at-risk percentage for each trade's package, using the same case project data. This is discussed next.

\section{Case project}

A Medium size property development company with a long experience to build compounds decides to build a compound of 100 identical houses. For the first time, the company decided to deliver this 


\section{This research is accepted to be published in ECAM journal DOI (10.1108/ECAM-04-2019-0222)}

project using BIM to prepare all the project documents including design, cost estimation and project schedule. The specification of each house is as follows: (1) the gross floor area is about $192 \mathrm{~m}^{2}$; (2) the house has a single floor; (3) from reviewing the Revit architectural plan, the spaces are a master bedroom with its own facilities of a bathroom and a robe room, three bedrooms, large living room, kitchen, dining room, another bathroom, family room and utility room.

The project works are categorised into five trade packages (general works, and ceiling, lighting fixture, finishing, and doors and windows packages). All trade contractors have experience with the same clients, that's why they all accepted to participate in such new procurement route with accepting the potential risks, all works have been conducted by those trade contractors and there were no any subcontractors participated in the project. The client intends to use IPD for delivering the project due to it is highly recommended since this approach has been successful in delivering similar projects and achieved acceptable performances regarding cost and schedule (Mesa et al., 2016, Trach et al., 2019). In forming the core project team, an architectural firm and five trade contractors are appointed to build the project's core group, as well as involving trade contractors to obtain the required information during kick-off meetings. Given, the client—Property development company—has previous experience with many trade contractors, therefore, all participated trade contractors have been selected according to their previous performances. As discussed, the IPD approach relies on sharing the benefits and risks; hence, it is important to determine all expenses and costs and assign them to specific activities. The team has utilised the traditional cost estimation way with BIM to conduct their estimation tasks in their project, however, the significant fluctuations of the achieved risk/reward among trade packages under similar construction environment generated a question regarding the cost estimation/allocation for project packages. Accordingly, in this research, the proposed framework will be applied to enable all parties gather in one cost pool under a cooperative joint venture, and the costs, from conceptualisation stage to buyout stage, can be determined, as discussed in the next section.

\section{Developing the framework}




\section{This research is accepted to be published in ECAM journal DOI (10.1108/ECAM-04-2019-0222)}

Integrated project delivery (IPD) has five pre-construction stages: conceptualisation, outline design, detailed design, documentation and buyout (AIA, 2007). The proposed framework therefore involves tools to manage cost estimation at each of these stages, as described next.

\section{Conceptualisation and outline design with TVD}

The conceptualisation and outline design stages begin by forming the core project team: the owner, the architect, the main contractor and trade contractors. Given that TVD relies on developing the design according to a restricted budget, any change or new added element triggers a round of estimation for predicting the total cost. Key decisions about the project reflect owner's requirements, as well as, any design criteria at hand. Therefore, a conceptual BIM model - architectural and engineering intentions - is created, using an authoring tool (i.e. Autodesk Revit or Graphisoft ArchiCAD). This BIM model is used to obtain indications of the proposed quantities and identities. At this stage, project information includes much uncertainty: consequently, the cost estimation model is presented in the form of a range of total costs against the degree of certainty through Monte Carlo Simulation (due to its ability to deal with different types of cost data distribution). Once the architect has developed the BIM conceptual model, the quantity surveyor must begin to extract the quantities and type of the proposed materials/components. A BIM tool, such as Autodesk Navisworks, can be used:

- Navisworks in XML format, extracts quantities to build the pricing sheet (using Microsoft [MS] Excel) and prepare the proposed initial price sheet of materials. Given that TVD requires continuous cost estimation feedback, therefore, BoQ will be extracted from the BIM model regularly while the design is developing.

The quantity surveyor collects the required cost data from the main contractor and trade contractors to build statistical samples of the labour and equipment required to perform the proposed design elements. These data include the range of material prices to draw reliable samples for each BIM design element, and allowances of labour and equipment that will be required to execute BIM design elements (preferred using analogous estimation (Amos, 2004), 


\section{This research is accepted to be published in ECAM journal DOI} (10.1108/ECAM-04-2019-0222)

as most of project parties in IPD join the conceptualisation stage, therefore, the data should be easily accessible);

- The quantity surveyor explores the type of statistical distribution that will be compatible with the collected data (normal, beta, etc.);

- The quantity surveyor identifies each proposed cost element to estimate the total value of all distributed elements and to enable the simulation to run;

- When the simulation starts to run, the extracted graphs show the total costs for the project, corresponding to the percentage of certainty of the input data.

Formulation of statistical model: to determine the proposed total cost, following equations are applied. Equation (1) represents the total cost that must be collected for each design element $D$ to assign the package cost for contractor $j$ :

$$
P C_{D j}=I Q P+\forall L_{B M} \& E_{B M}
$$

Equation (1)

where $P C_{D j}$ is the proposed cost for the design element $D$ that is proposed to be assigned to contractor $j$; IQP is the initial quantity prices for $D j ; L_{B M} \& E_{B M}$ are the labour and equipment price for the best scenario $B$ for the specific material $M$.

The statistical model requires a wide range of proposed values to enable a reliable total cost to be obtained. Equations (2.1), (2.2) and (2.3) therefore show how BIM data are integrated into Monte Carlo Simulation. These equations rely on using beta distribution, however, if a wider range of prices is used, these equations are extended to provide a more accurate material cost:

$$
\begin{aligned}
& I Q P_{A V M}=I Q_{B I M \text { conceptual model }} \times R P_{M} \\
& I Q P_{O P M}=I Q_{B I M \text { conceptual model }} \times O P_{M} \\
& I Q P_{P M}=I Q_{B I M \text { conceptual model }} \times P P_{M}
\end{aligned}
$$

where $I Q P$ represents the initial quantity prices for average, optimistic and pessimistic values; $I Q$ is the initial quantities extracted using BIM tools; while $R P_{M}$ is the recent price for material $M ; O P_{M}$ is the optimistic price for material $M$; and $P P_{M}$ is the pessimistic price for material $M$. Other costs such 


\section{This research is accepted to be published in ECAM journal DOI}

(10.1108/ECAM-04-2019-0222)

as labour and equipment can be easily collected using IPD core team members, drawing upon their early involvement. Equation (2.4) shows the formula for calculations:

$$
\forall L_{B M} \& E_{B M}=U P_{M} \times T U_{M}
$$

where $L_{B M} \& E_{B M}$ are the labour and equipment price for the best scenario $B$ for specific material $M$; $U P_{M}$ is the unit price for material $M$; and $T U_{M}$ is the total units for material $M$. Equation (2.5) is another version of Equation (2.4) to capture the worst case scenario, as follows:

$$
\forall L_{W M} \& E_{W M}=U P_{M} \times T U_{M}
$$

where $L_{W M} \& E_{W M}$ are the labour and equipment price for the worst case scenario $W$ for specific material $M$. To complete the beta distribution, the average value is determined as in Equation (2.6):

$$
\forall L_{A V M} \& E_{A V M}=\frac{\left(\forall L_{B M} \& E_{B M}+\forall L_{W M} \& E_{W M}\right)}{2}
$$

Figure 2 shows the interoperability and the process of integrating BIM data into Monte Carlo Simulation to obtain the proposed material cost. Based on the data and using analogous cost estimation or expert judgement from core team members, the cost range of the statistical model is determined. For example, if core team members agree that three values for each cost element are reliable, the distribution is loaded for three probable costs. Based on the pre-identified range of costs, the distribution system is selected. The three values mentioned above are consistent with the beta and normal distributions. 


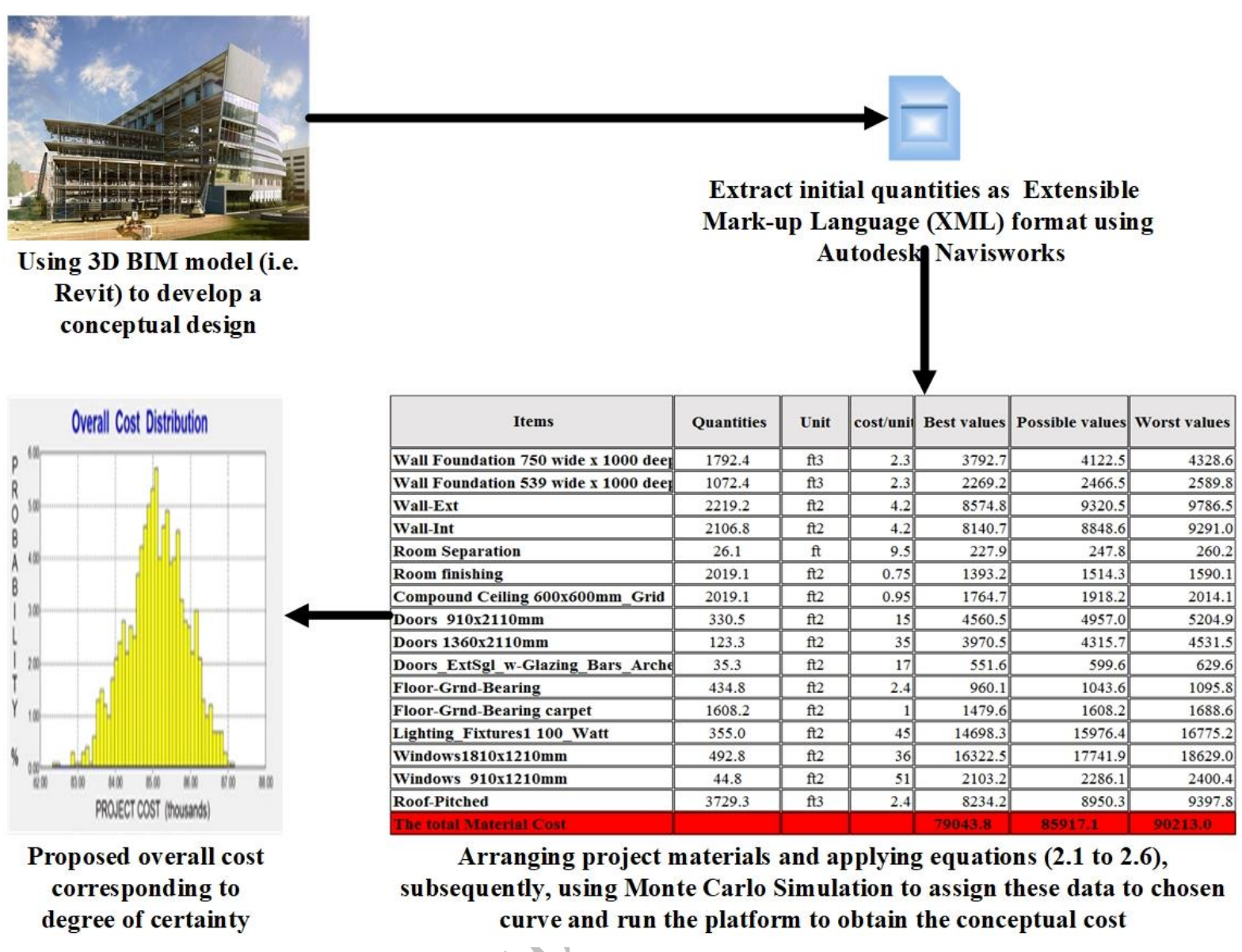

Figure 2. Cost estimation within conceptualisation and outline design stages

Obtaining proposed entirecost against certainty percentages: at this stage, the model is ready to run.

Monte Carlo Simulation has two important features, the first of which is the total cost, corresponding to the degree of certainty. This cost range is necessary for developing the business case for the client, based on the TVD system, before moving to the detailed design stage, as recommended by Allison et al. (2017). The second feature is the sensitivity analysis chart that presents the degree of importance of each project design element. This is vital for supporting decisions regarding the use of sensitive elements in the design. Through these features, the necessary data are available for making the right decision; therefore, the client can decide whether the proposed whole cost is located within the allowable budget. Once the client has approved the proposed cost, the project moves to the detailed design stage in which another cost estimation strategy is used. 


\section{This research is accepted to be published in ECAM journal DOI (10.1108/ECAM-04-2019-0222)}

If the client does not approve the proposed cost, an ongoing negotiation is necessary to fulfil any client's requirements. The sensitivity analysis chart plays a key role here, identifying the elements that are sensitive in increasing the cost, and seeking to minimise the cost by targeting these elements.

\section{Detailed design stage}

Detailed design, in which the most significant part of the project information is formulated, is the most vital stage of IPD (Allison et al., 2017). In this stage, the 3D BIM model is enhanced by adding other dimensions: scheduling (4D BIM) and cost (5D BIM). The precise bills of quantities (BoQs) are then extracted using Navisworks in XML, with these including data of various natures for each element, such as geometry, dimensions, the model hierarchy, etc. The quantity surveyor next collects the corresponding unit price of each element used, in order to move to the documentation stage - with adequate information - and to prepare a reliable cost structure.

\section{Documentation and buyout stages}

As discussed, IPD cost structure relies on distinguishing all cost elements, such as direct, indirect and overhead costs, given that any risk/rewards is determined based on the rate of achievement of each individual element. To extend this, according to AIA (2007), the overhead cost represents a separate limb after the direct and indirect limbs, and the final limb is the profit-at-risk percentage. The risks/rewards are determined based on the progress of each individual limb (i.e. whether the progress indicates a cost saving or is located as a profit-at-risk percentage). However, if progress indicates that the expanded cost exceeds three limbs, client is responsible only for the direct cost. Therefore, as discussed, having a scrutinising costing system is vital for successful IPD delivery.

Here, adopting the $\mathrm{ABC}$ approach provides a solution, with each stakeholder involved from the conceptualisation stage. Moreover, throughout the first three IPD stages, all stakeholders, even trade contractors, participate in determining the cost of the project. The overhead costs represent a significant proportion of the whole project cost, with these costs for each construction package able to be obtained from the activities required to proceed with that package. Therefore, the ABC system can allocate overhead costs to relevant activities to determine the overhead resources for each package. 


\section{This research is accepted to be published in ECAM journal DOI}

(10.1108/ECAM-04-2019-0222)

Figure 3 illustrates the comparison between the traditional $\mathrm{ABC}$ hierarchy levels and the proposed IPD based on $\mathrm{ABC}$ adapted levels to follow overhead resources within the defined and specific levels.

As a result, overhead resources required at different levels can be evaluated.
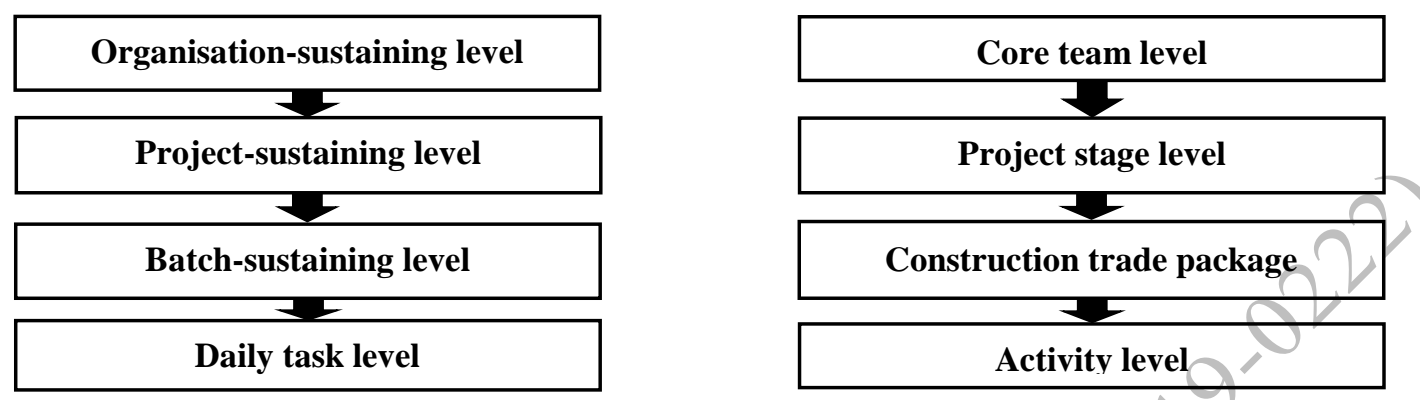

Figure 3. ABC functional level: Comparison between traditional delivery approach (left) and IPD approach (right)

Overhead costs, such as inspection and quality control as well as cost control reports, should be converted into a unit that can be allocated as per its proportion of the cost driver. This process can generate an accurate cost estimation value for each trade package (i.e. civil package, mechanical package, electrical package, etc.). The target cost in the IPD payment method is fair for each package/party in the IPD project as some packages require a low consumption rate of overhead resources, while for others, a high consumption rate of overhead resources is required regardless of their proportion of the entire project. Nevertheless, the consumption of this significant proportion of overhead costs is needed; thus, it is imperative that these costs be allocated to overhead activity consumption.

Activity-based costing $(A B C)$ estimation sheet: the proposed coding system is developed to work as a bridge between $\mathrm{ABC}$ and BIM tools. The data is semi-automated moved from 4/5D BIM models to the developed $\mathrm{ABC}$ sheets through exporting the activities with the corresponding costs as XML format and subsequently importing these activities to the $\mathrm{ABC}$ sheet that has been developed using MS Access. It includes digital numbers as well as alphabetical letters. According to the adapted ABC based IPD levels presented in the figure 4, there are four levels will be presented as 010 for daily task level, 020 for the package level, 030 for the project stage level, and 040 for the IPD core team member. The project package will be identified using the initials of its names, for example the daily task level for the general 


\section{This research is accepted to be published in ECAM journal DOI}

(10.1108/ECAM-04-2019-0222)

package is 010G. The presented data entry form in the figure 4 enables the cost estimator to enter the data using the developed lookup field that is designed based on ABC based IPD hierarchy levels.

\begin{tabular}{|c|c|}
\hline CenS4 & ABC Sheet \\
\hline \multicolumn{2}{|l|}{ Codes } \\
\hline \multicolumn{2}{|l|}{ Activities } \\
\hline \multicolumn{2}{|l|}{ Task type } \\
\hline \multicolumn{2}{|l|}{ Cost driver } \\
\hline Units & 0 \\
\hline Cost unit/Cost driver & $£ 0.00$ \\
\hline \multicolumn{2}{|l|}{ Total Cost } \\
\hline \multicolumn{2}{|l|}{ LIMB2 } \\
\hline \multicolumn{2}{|l|}{ Project parties } \\
\hline \multicolumn{2}{|l|}{ Overhead Consumpti 0} \\
\hline \multicolumn{2}{|l|}{ Actual Overhead Cos } \\
\hline \multicolumn{2}{|l|}{ CSoOOA } \\
\hline \multicolumn{2}{|l|}{ CSOOPA } \\
\hline \multicolumn{2}{|l|}{ TCSoOC } \\
\hline 䝧 & 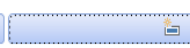 \\
\hline
\end{tabular}

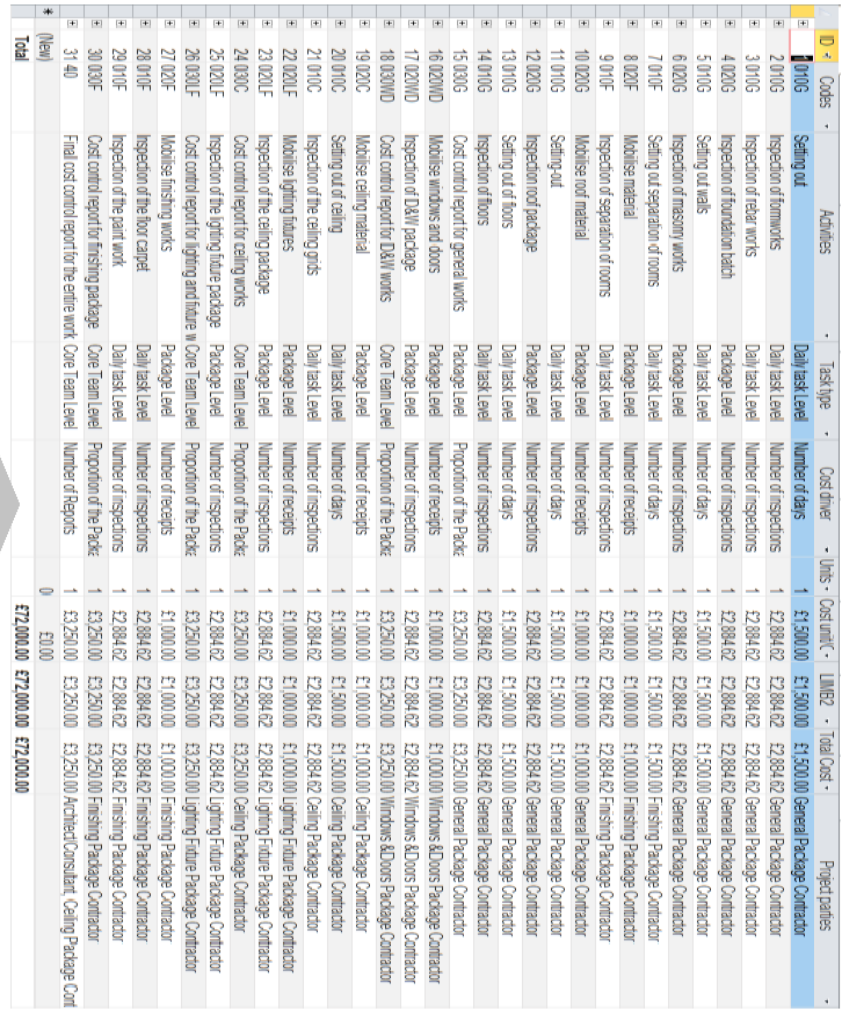

Figure 4. ABC structure sheet based IPD approach

Formulation of the IPD-based ABC model: during the buyout stage, each party needs to know the cost structure of the proposed works, with Equations (3), (4) and (5) able to be used to determine the total cost of each limb. Extracting BoQs using Navisworks is followed by pricing the extracted quantities and adding productivity allowances (labour and equipment) to complete the project pricing. Equations (3), (4) and (5) are used to categorise the estimated costs into three limbs for each package using the proposed coding system, as discussed below.

Equation (3) shows the structure of Limb 1, including direct and indirect costs, with these two terms able to be automatically estimated for each package (participant) through extracting costs using the coding system from the $\mathrm{ABC}$ sheet (see the Appendix).

$$
L I M B 1_{i j}=\sum_{i=1}^{n}\left(\operatorname{CoD} A_{K j}+\operatorname{CoI} A_{K j}\right)
$$




\section{This research is accepted to be published in ECAM journal DOI}

(10.1108/ECAM-04-2019-0222)

where $L I M B 1_{i j}$ represents the direct and indirect costs for trade contractor $i$ to perform trade package $j ; \operatorname{CoD} A_{K j}$ represents the cost of direct activity for design element $k$ and trade package $j$; and $\operatorname{CoI} A_{K j}$ represents the cost of indirect activity for design element $k$ and trade package $j$.

Equation (4) shows the structure of Limb 2, representing overhead costs as the summation of the number of overhead activities for each package multiplied by the cost driver's estimated costs. For the purpose of automation, all costs can be automatically extracted from the ABC sheet (see Appendix).

$$
L I M B 2_{O A}=\sum_{i=1}^{n}\left(N O A_{O A} \times M V o C D_{D A}\right)
$$

where $L I M B 2_{O A}$ represents the overhead costs of specific operation $O$, such as cost control to perform overhead activity $A ; N O A_{O A}$ represents the summation of the number of operations $O$ needs to perform in overhead activity $A$; and $M V O C D_{D A}$ reflects the monetary value of cost driver $D$ performing overhead activity $A$.

Equation (5) represents the structure of Limb 3, which can be estimated by adding the profit-at-risk percentage (P@R\%) to the pre-estimated Limbs 1 and 2.

$$
L I M B 3_{i j}=\sum_{i=1}^{n}\left(L M B 2 \& 3_{i j}\right) \times P @ R \%_{i j}
$$

where $L I M B 3_{i j}$ is the profit-at-risk percentage for trade contractor $i$ to implement specific trade package $j ; L M B 2 \& 3_{i j}$ reflects the total costs for each package assigned to a specific party in the buyout stage; and $P @ R \%_{i j}$ represents the profit-at-risk percentage for trade contractor $i$ to implement trade package $j$. 


\section{Package's cost structure}

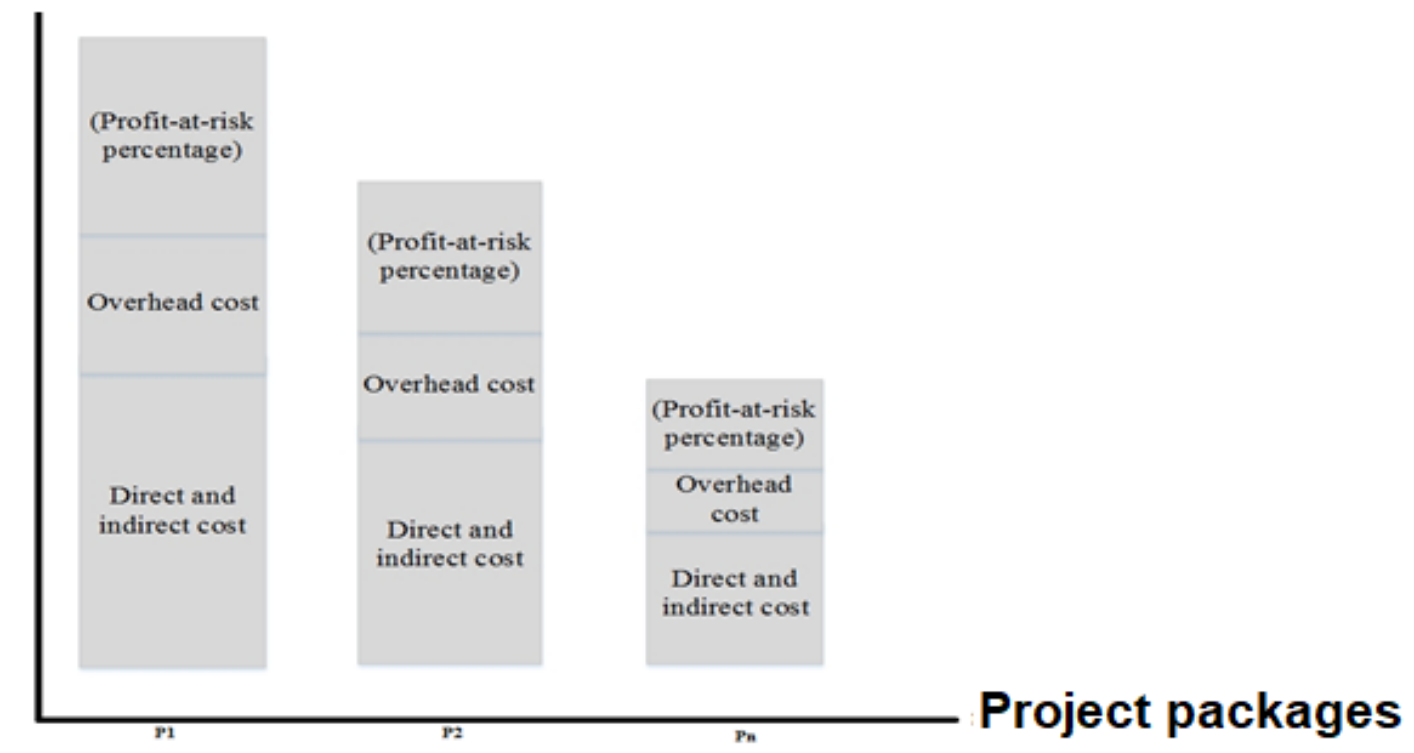

Figure 5. Structure of IPD cost estimation for each party

According to Allison et al. (2017), splitting all overhead resources in a single pool can help to avoid waste when some project members implement more work than is required. On the other hand, determining overhead resources for a separate limb minimises the opportunity to hide a proportion of profit in the overhead percentage (Allison et al., 2017). As all non-owner parties carry the same level of responsibility, the relationships between contractors and other parties are at the same level of inference. Therefore, as illustrated in Figure 5, the estimation for each party is individually delivered.

The IPD approach requires the completion of several tasks prior to the construction stage. Figure 6 illustrates these tasks: the cost estimation process within conceptualisation, outline and detailed design, and documentation stages; methods and tools to deal with various types of data; the amount of cost data to be analysed; the input and output of each stage; and the proposed tool to analyse the available data.

The cost estimator can adopt the below flowchart as a map to direct the estimation process during the pre-construction stage. Given that the IPD relies on the TVD technique to manage the design process, therefore, during the conceptualisation stage, the conceptual 3D BIM model should be built and a 
This research is accepted to be published in ECAM journal DOI

(10.1108/ECAM-04-2019-0222)

continuous cost estimation feedback is needed. That's why, the Monte Carlo simulation based BIM as developed in the framework (Conceptualisation and outline design stages) should be followed.

Afterwards, the detailed 3D BIM design will be accomplished and the cost estimator should begin use. 
This research is accepted to be published in ECAM journal DOI (10.1108/ECAM-04-2019-0222)
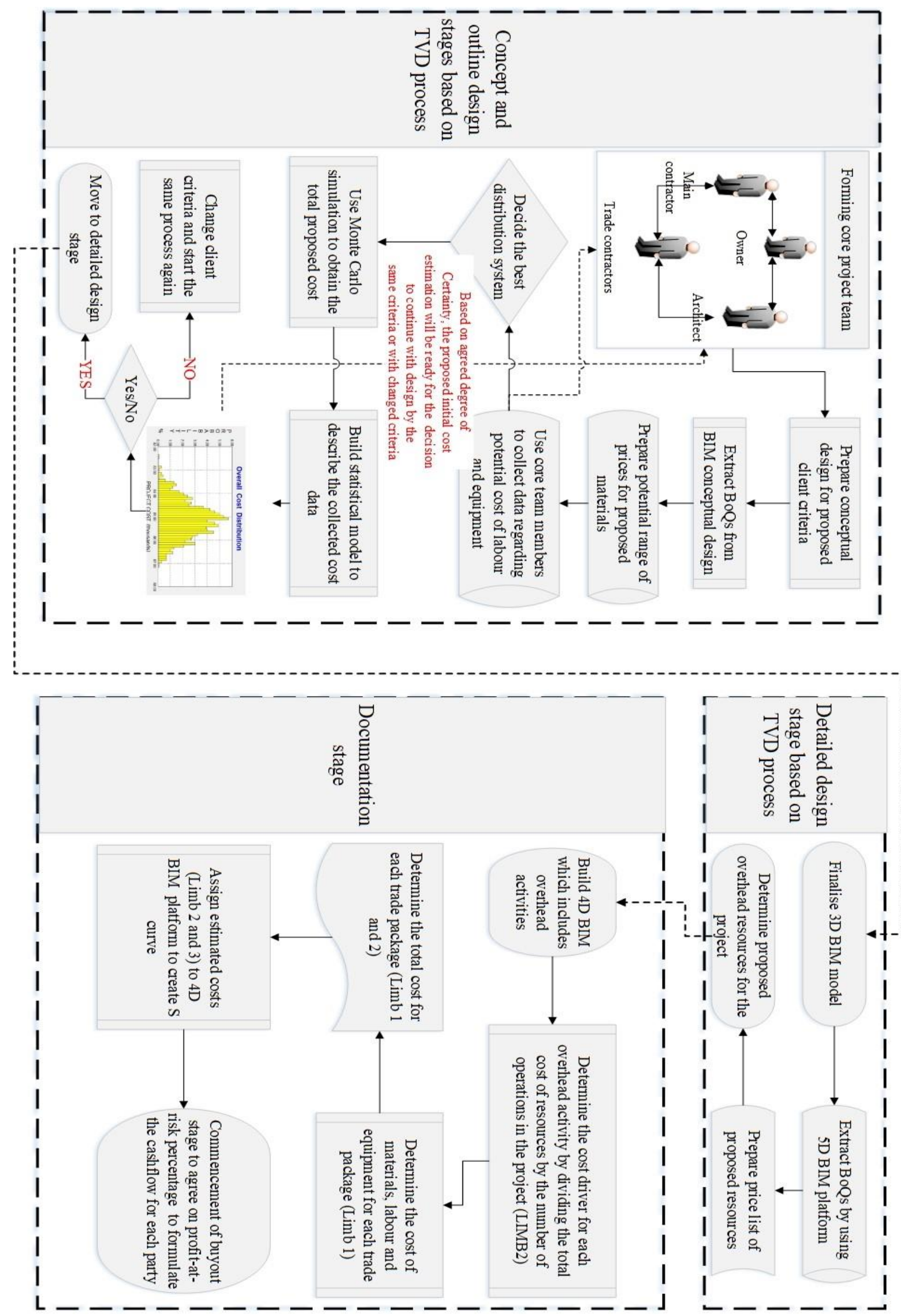

Figure 6. Cost estimation data flow within IPD pre-construction stages 


\section{The case study}

\section{Initial cost estimation at outline design stage}

The graphs in Figure 7 illustrate the total material and labour costs and were prepared by a Monte Carlo simulation after the cost data were collected by the IPD core team's quantity surveyor, with beta distribution used to distribute these cost elements. The output from this process is the total costs graph, showing how the total cost corresponds to a specific certainty percentage. Moreover, the sensitivity analysis charts reveal the impacts of each cost element in the project, thus determining each element's importance in the detailed design stage and the execution process. The client makes decisions based on these outputs and, if the client accepts the solution, the project progresses to the detailed design stage. If the client does not accept the solution, the client/quantity surveyor can alter the requirements by changing the cost elements and repeating the process.

In the case project, the decision-making scope reveals that the cost will be almost $£ 103,000$, while the actual case study states that the direct and indirect costs total $£ 118,484$. The deviation between the decision-making scope and the precise cost estimation is about $12 \%$ : this level of deviation is more acceptable at the feasibility study and budget authorisation stages, in accordance with class 3 of the cost estimate classification matrix deyeloped by Amos (2004), with this class accepting a deviation below detailed estimation of from $-10 \%$ to $-20 \%$. 
This research is accepted to be published in ECAM journal DOI

(10.1108/ECAM-04-2019-0222)
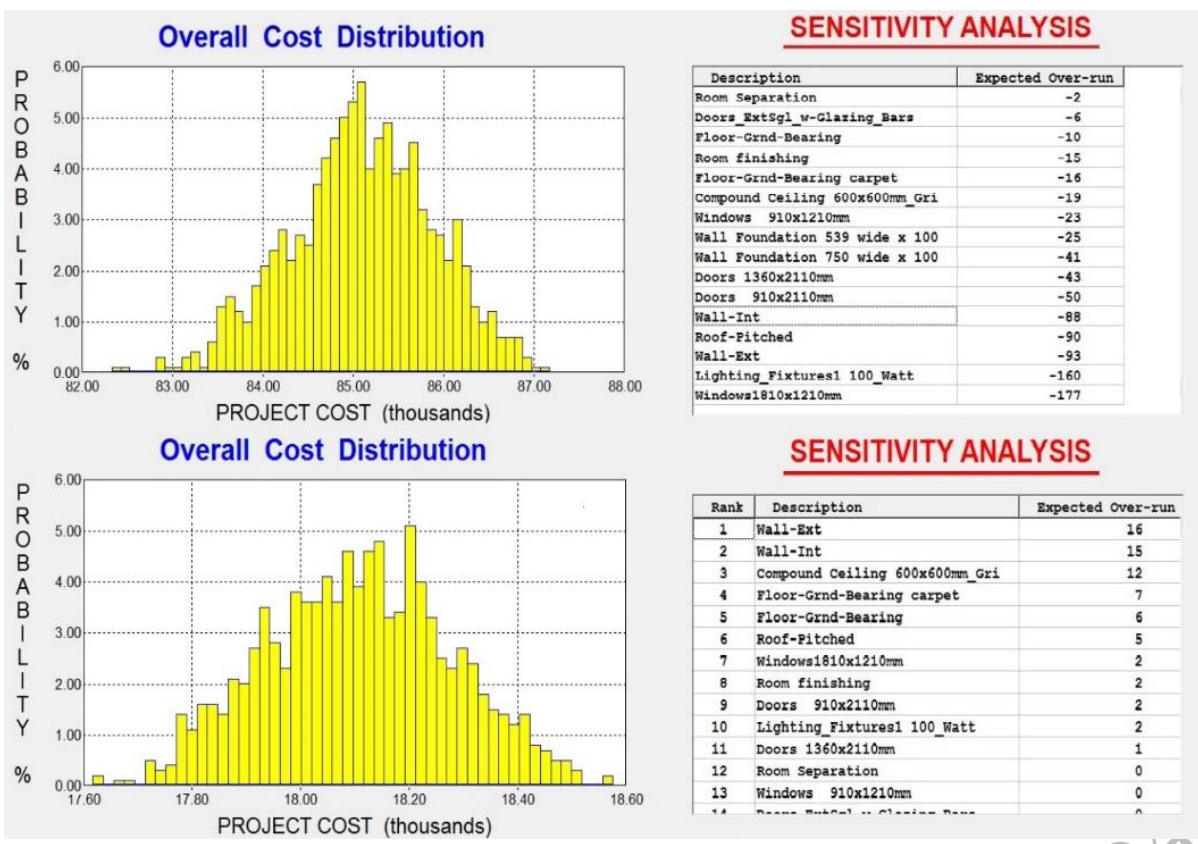

Figure 7. Total material and labour costs prepared by Monte Carlo simulation

\section{Cost estimation during detailed design stage}

After finalising the 3D BIM model, the estimator begins to use this model for detailed cost estimation by importing it to a 5D BIM platform to extract the quantities and move to the pricing stage. Based on the agreed-upon length of the contract, the overhead resources are determined to enable the costing process. The proposed resources and those resources needed to perform each activity are presented in figure 8 .

\begin{tabular}{|c|c|c|c|c|c|}
\hline \multicolumn{2}{|c|}{ Y } & ID & Function & Salary & Overhead Activity . \\
\hline & $\oplus$ & & 1 Quantity Surveyor & $£ 12,000.00$ & Cost control \\
\hline & + & & 2 Quality control engineel & $f 9,000.00$ & Inspection \\
\hline & $\oplus$ & & 3 Quality assurance engin & $£ 9,000.00$ & Inspection \\
\hline & + & & 4 Accountant & $£ 7,500.00$ & Cost control \\
\hline & $\oplus$ & & 5 Project manager & $£ 12,000.00$ & Inspection \\
\hline & + & & 6 Site engineer & $£ 9,000.00$ & Setting out \\
\hline & 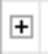 & & 7 Supervisor & $£ 7,500.00$ & Inspection \\
\hline & 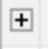 & & 8 Warehouse manager & $£ 6,000.00$ & Mobilising \\
\hline \multirow[t]{2}{*}{ 米 } & & (New) & & $£ 0.00$ & \\
\hline & & Total & & $£ 72,000.00$ & \\
\hline
\end{tabular}

Figure 8. The needed resources needed to perform each activity 


\section{This research is accepted to be published in ECAM journal DOI (10.1108/ECAM-04-2019-0222)}

Therefore, the cost drivers can be determined as the total cost of each operation is divided by the number of operations (activities) in the project (see figure 9 below for details).

\begin{tabular}{|c|c|c|c|c|c|c|}
\hline \multicolumn{2}{|c|}{ 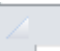 } & Overhead Activity . & Number of needed processes & 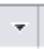 & Value of overhead resources & Value of overhead $\hat{c}$. \\
\hline & $\oplus$ & Cost control & & 6 & $£ 19,500.00$ & $£ 3,250.00$ \\
\hline & 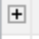 & Inspection & & 13 & $£ 37,500.00$ & $£ 2,884.62$ \\
\hline & $\oplus$ & Mobilising & & 6 & $£ 6,000.00$ & $£ 1,000.00$ \\
\hline & $\oplus$ & Setting out & & 6 & $£ 9,000.00$ & $£ 1,500.00$ \\
\hline 米 & & & & 0 & $£ 0.00$ & \\
\hline
\end{tabular}

Figure 9. Values of cost drivers

\section{Calculations of cost drivers/ cost units}

The inspection process requires a quality control engineer, quality assurance engineer, supervisor and a project manager. In total, 13 inspection activities are needed during the project. The mobilisation process occurs six times during the project, with the warehouse manager assigned this responsibility.

Cost control needs a quantity surveyor and an accountant and is run six times during project execution. Setting out is run six times during the project, with the site engineer having responsibility for its implementation.

\section{Integrated project delivery (IPD) cost structure}

With the extracted quantities priced, material costs are ready and the summary of each trade package's materials are presented, as illustrated in Table 1. Moreover, other labour and equipment resources are determined using the same MS Excel spreadsheet, as summarised in Table 1. Limb 1 is thus ready and the estimator should move to Limb 2 which pertains to overhead costs. Table 1 summarises both the cost estimation approaches, namely, the traditional costing system and the use of $\mathrm{ABC}$ estimation to validate the significance of the developed framework in presenting reliable cost estimation in the detailed design stage. 
This research is accepted to be published in ECAM journal DOI

(10.1108/ECAM-04-2019-0222)

Table 1. Compensation structure components

\begin{tabular}{|c|c|c|c|c|c|c|}
\hline $\begin{array}{l}\text { Table } \\
\text { sections }\end{array}$ & $\begin{array}{l}\text { Construction } \\
\text { packages }\end{array}$ & $\begin{array}{c}\text { General } \\
£\end{array}$ & $\begin{array}{l}\text { Ceiling } \\
£\end{array}$ & $\begin{array}{l}\text { Lighting } \\
\text { fixture } \\
£\end{array}$ & $\begin{array}{c}\text { Finishing } \\
£\end{array}$ & $\begin{array}{c}\text { Doors and } \\
\text { windows } \\
£\end{array}$ \\
\hline \multirow{4}{*}{ 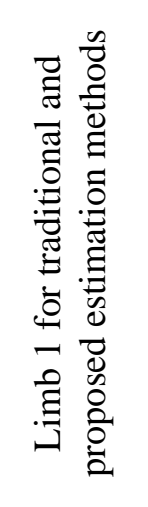 } & $\begin{array}{l}\text { Total material } \\
\text { costs }\end{array}$ & $38,038.9$ & $2,140.2$ & $17,037.9$ & $3,553.8$ & $31,919.1$ \\
\hline & Total labour costs & $21,318.9$ & 1,715 & 296.5 & $1,334.4$ & \\
\hline & $\begin{array}{l}\text { Total equipment } \\
\text { costs }\end{array}$ & 366.8 & 0 & 0 & 0 & \\
\hline & $\begin{array}{l}\text { Total direct and } \\
\text { indirect costs } \\
\text { (Limb 1) }\end{array}$ & $59,724.7$ & $3,855.2$ & $17,334.4$ & $4,888,3$ & $32,682.2$ \\
\hline \multirow{4}{*}{ 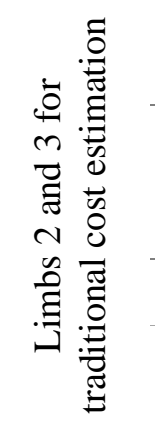 } & $\begin{array}{l}\text { Proportion of } \\
\text { overhead costs }\end{array}$ & 0.533 & 0.031 & 0.138 & 0.039 & 0.260 \\
\hline & $\begin{array}{l}\text { Total } \\
\text { overhead/package } \\
\text { (Limb 2) }\end{array}$ & 38,377 & 2,206 & 9,919 & 2,797 & 18,701 \\
\hline & Total costs & 98,102 & 6,061 & 27,253 & 7,685 & 51,383 \\
\hline & $\begin{array}{l}\text { Profit-at-risk limit } \\
\text { (Limb 3) }\end{array}$ & $19,620.4$ & 1212.2 & 5450.6 & 1537 & 10276.6 \\
\hline \multirow{3}{*}{ 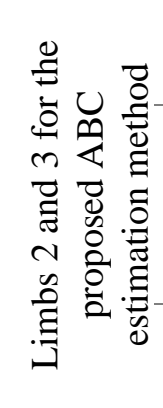 } & $\begin{array}{l}\text { Overhead costs } \\
\text { (Limb 2) }\end{array}$ & $27,557.6$ & $11,519.2$ & $7,134.6$ & $15,403.8$ & $7,134.6$ \\
\hline & $\begin{array}{l}\text { Total costs }(\mathrm{ABC}) \\
\text { (starting point of } \\
\text { profit-at-risk } \\
\text { percentage) }\end{array}$ & $89,014.7$ & $15,474.1$ & $24,916.7$ & $20,418.4$ & $40,660.9$ \\
\hline & $\begin{array}{l}\text { Profit-at-risk limit } \\
\text { (Limb 3) }\end{array}$ & $106,817.6$ & $18,568.9$ & $29,900.1$ & $24,502.1$ & $48,793.1$ \\
\hline
\end{tabular}

With the cost of each package as shown in Table 1, the total project cost is $£ 190,484$. The overhead costs represent about $37.8 \%$ of the total costs: this requires a very precise allocation so the actual target cost for each package can be determined and the package can be sold to the buyer at a fair price. Moreover, when the project is completed, the project parties need to know whether each package has achieved cost savings or not, and to be able to determine the percentage of cost savings so the rewards can be allocated fairly between the project parties. Each package includes various activities which have different expenditure on overhead costs from one package to the next. For instance, the concrete package needs to be inspected three times: after the formwork, the rebar and the concreting. In 
This research is accepted to be published in ECAM journal DOI

(10.1108/ECAM-04-2019-0222)

contrast, the doors and windows package only needs one inspection to ensure that the installation is according to the requirements and so the package can be delivered to the main contractor. Moreover, if any other package depends on the completion of this specific package, a delivery inspection is also needed.

Given that the researcher has presented the outcome of the estimation using the proposed framework against the existing cost estimation values for the same design (3D BIM model), therefore, this enables the company practitioners to measure the significance of the proposed cost estimation approach. Moreover, the researcher presented the framework in applicable tools, therefore, this will encourage practitioners to implement the framework in their future projects.

\section{The application of the developed cost estimation tool}

Figure 10 shows a snapshot of the developed cost estimation tools based the framework. It includes the calculations of the three $\operatorname{LIMB}(\mathrm{s})$. 
This research is accepted to be published in ECAM journal DOI (10.1108/ECAM-04-2019-0222)

\begin{tabular}{|c|c|c|c|c|c|c|}
\hline \multicolumn{7}{|c|}{ III LIMB-1 (Direct and indirect cost: } \\
\hline & Codes & Construction Package - & MC-Based BIM & LC-Base-d B:IM & Equipicost-Based BIM . & LIMBI \\
\hline & FWLIMB-1. & Finis hilng Package & $13,553.80$ & $E 1,334.40$ & 50.00 & $64,888.20$ \\
\hline & LFWIMMB- 1 & Lighting Fixtu re Package & $£ 17,037.90$ & $\$ 296.50$ & 60.00 & $£ 17,334.40$ \\
\hline & WDWUIMB-1 & Windows andil Dowors Packag & $£ 31,919.10$ & $\mathrm{f} 763.00$ & $£ 0.00$ & $\mathrm{f} 32,682.10$ \\
\hline * & & & $£ 0.00$ & $E 0.00$ & $£ 0.00$ & \\
\hline
\end{tabular}

\section{LIMB-1 (Direct and Indirect Costs)}

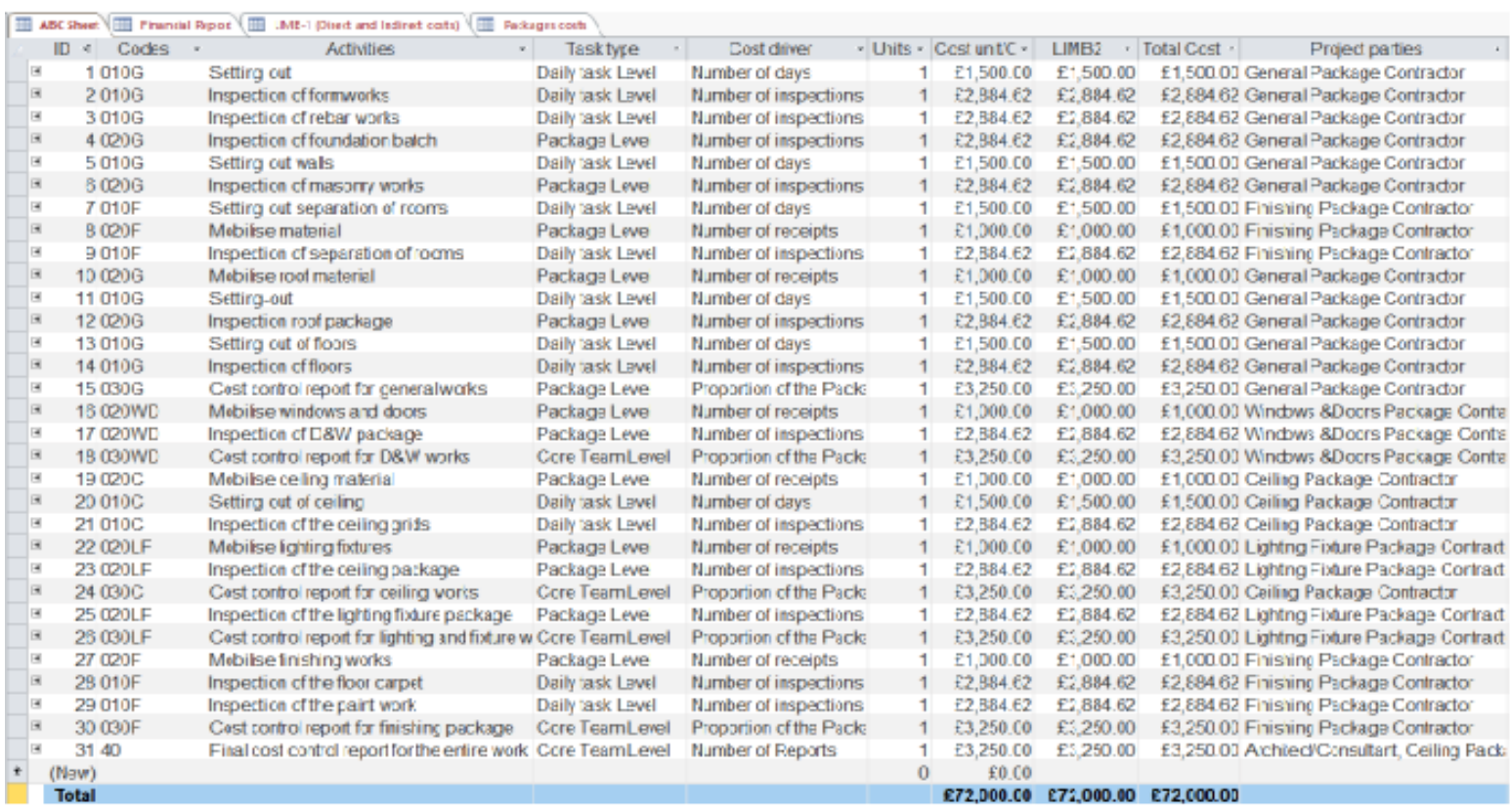

\section{LIMB-2 (Overhead Costs)}

\begin{tabular}{|c|c|c|c|c|c|c|c|c|}
\hline \multicolumn{9}{|c|}{ 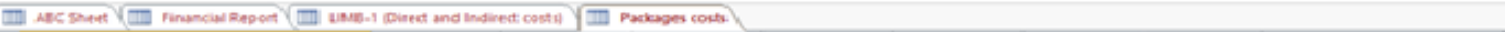 } \\
\hline & Finshing Works contractor & $E 4,838.30$ & $4.135 \mathrm{~s}$ & E134.07 & $615,403.00$ & 40635.23464 & $€ 20,426.17$ & $524,511,41$ \\
\hline & General Works contractor & Es,724.70 & S0.40\% & E1,633.09 & $277,557.60$ & 2772407822 & 638.920 .39 & $6106,704.47$ \\
\hline • & & 100,00 & & & 60.60 & & & \\
\hline & Eotal & $118,004-400$ & $\infty .0006$ & $0,260.00$ & $688,749.00$ & 1309 & $90,490.60$ & 2035.591.52 \\
\hline
\end{tabular}

\section{Cost structure of all packages}

Figure 10. The application of the developed cost estimation tool

\section{Discussion of the findings}

As can be seen in Figure 11, Limb 1 is similar in both the traditional method and ABC estimation.

However, the overhead cost differs between these two methods. The fluctuation percentage between

$\mathrm{ABC}$ estimation and traditional cost estimation is higher than $100 \%$ in the finishing package, given 
This research is accepted to be published in ECAM journal DOI

(10.1108/ECAM-04-2019-0222)

that the case study project is relatively small with a limited number of activities, with the lowest level being $8 \%$ fluctuation in the lighting fixture package.
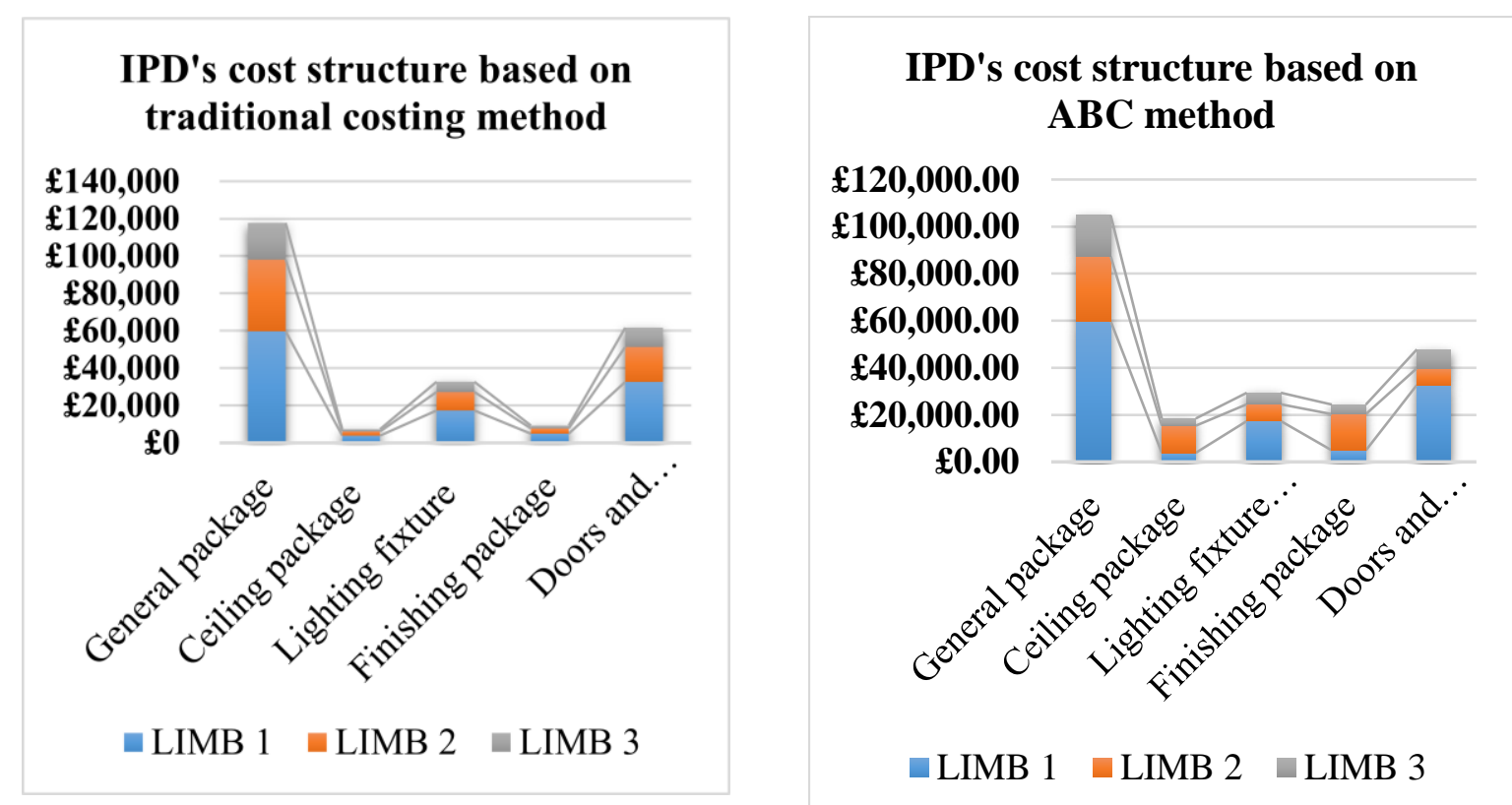

Figure 11. IPD cost structure using two costing methous

Figure 12 illustrates all deviations between using $\mathrm{ABC}$ estimation and traditional cost estimation for each package. To validate the significance of integrating ABC into IPD using BIM capabilities,

Figure 12 reveals that the deviation for Limb 3 values (the profit-at-risk percentage) has been elevated by $£ 2521.42$ for the finishing package, which is more than twice the value in the traditional method. However, other packages have decreased in value, such as the doors and windows package which is $22 \%$ lower than when traditional cost estimation was used. 


\section{This research is accepted to be published in ECAM journal DOI}

(10.1108/ECAM-04-2019-0222)

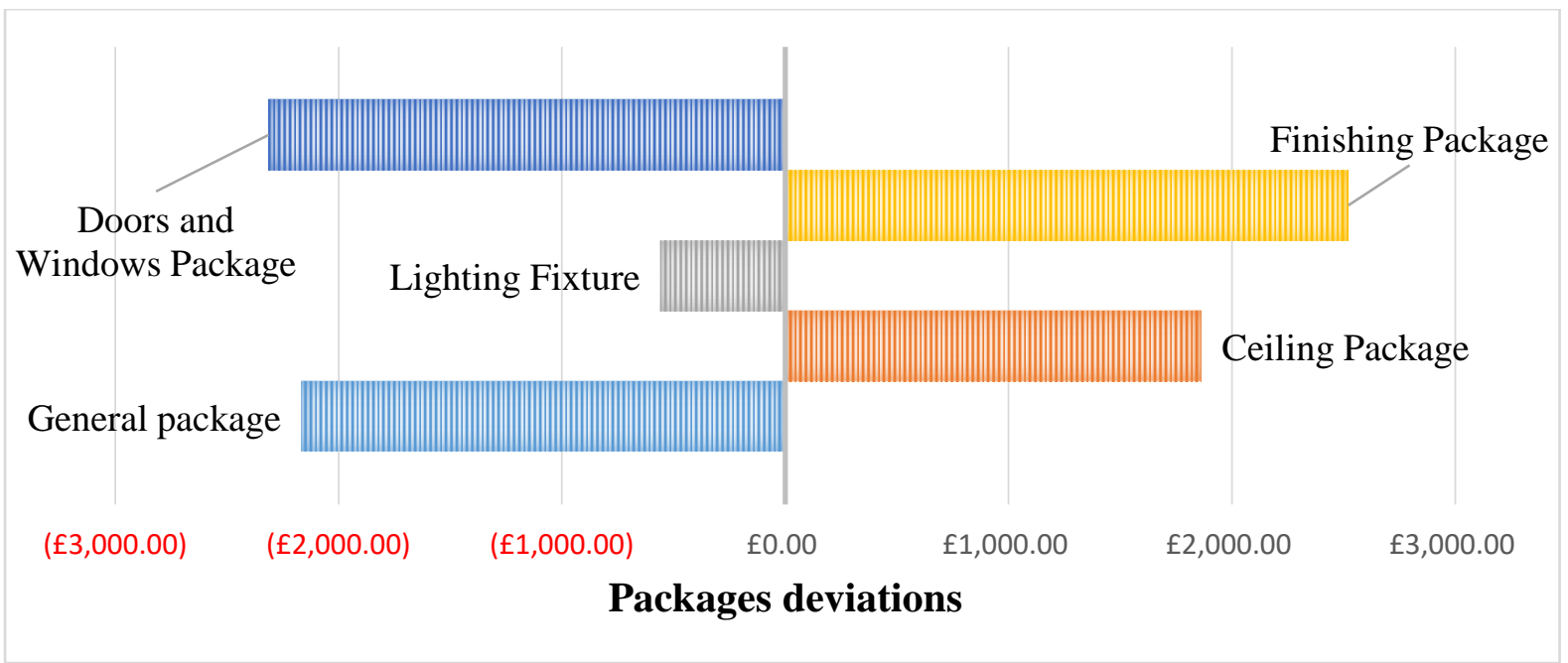

Figure 12. Deviations between $A B C$ estimation and traditional estimation for each package

In their study,Ballard et al. (2015) set out to identify the factors leading to the failure of risks/rewards sharing, with this research undertaken as a case study that comprised a $250,000 \mathrm{ft}^{2}$ patient care pavilion. The findings referred to cost overrun as the main reason, with the completed project having a cost overrun of almost $6.4 \%$ more than what had been planned; subsequently, the risk pool firms did not receive any profit. To reflect that case study's conclusion in the findings of the current research, the scrutiny of continuous cost estimation is vital to reveal any potential cost overrun at an early stage. If this is done, the source of the overrun can be defined with appropriate corrective action taken. Accurate cost estimation, as well as better allocation of resources among core project team members, can improve project implementation, thus preparing high-level evidence to prove any increase or reduction in cost. This requires a cost estimation method that can distinguish between all the different elements in the cost structure (i.e. direct, indirect and overhead costs).

The high degree of clarity in the proposed cost estimation could encourage contractors to take a part in the IPD projects. The proposed automated way of determining/allocating the overhead cost based on $\mathrm{ABC}$ could enhance the trust among the project parties. This study as it is presented as a quantitative comparison between two different estimation approaches provided a piece of evidence to the cost estimation practitioners, clients and contractors in terms of the importance of implementing such proposed framework to ensure the fair allocation of cost and developing a reliable compensation structure of the IPD project. 


\section{This research is accepted to be published in ECAM journal DOI (10.1108/ECAM-04-2019-0222)}

\section{Practical implications}

The study findings will be appealing to the world of practice in several ways:

- The proposed framework provides a workable solution for BIM-IPD integration, producing reliable cost data from different sources that are applicable to various project delivery modes. Using BIM to develop a conceptual model that addresses client criteria enables the estimator who is building the statistical models to obtain a range of proposed costs against a degree of certainty. These can all be translated into the innovative practices in real-life projects.

- The case study provides evidence of the viability of using a Monte Carlo Simulation integrated with BIM to develop a conceptual cost estimation: the deviation between the conceptual and detailed cost estimation did not exceed $12 \%$ which is considered acceptable at an early design stage. This will contribute to the conceptual cost estimation in general since the presented conceptual cost estimation approach is linked mainly with BIM, therefore, this will be valid for any project.

- The case study reveals that using $\mathrm{ABC}$ provides a better IPD cost structure and that the total prices of all packages fluctuate due to better overhead cost allocation after avoiding the traditional (proportional) method. This will encourage clients to use IPD to deliver their projects, as well as, the trade contractors will be more comfortable with IPD since the presented case study will raise their awareness about the importance of a fair cost allocation to ensure fair risk/reward sharing by the end of the project.

- This research presented a comprehensive solution for several practical issues that revealed while implementing it in several studies such as Roy et al. (2018b) who identified the main cost estimation challenges as the difference in the accounting of cost and profit among IPD core team members, therefore, this study responded to this point by proposing an integrated cost estimation tool that can be adopted by all team members, the proposed cost estimation tool is user-friendly since it is designed based $\mathrm{ABC}$ method and a smart $\mathrm{ABC}$ sheet is designed for the IPD approach. 


\section{This research is accepted to be published in ECAM journal DOI (10.1108/ECAM-04-2019-0222)}

- Given that all calculations are executed automatically using the proposed database system, this system offers a data entry forms that enables cost estimation practitioners to enter only the required inputs, accordingly, the cost estimation of every package will be determined automatically. This system has been developed to facilitate implementing such sophisticated estimation approach since $\mathrm{ABC}$ is not widely used in the construction industry and such automation tool will foster the adoption process into the industry. In order to ensure the applicability of the proposed cost estimation mathematical models based $\mathrm{ABC}$, the authors have developed all tools in the reality and the case study has applied using these tools - ABC sheets and its relevant calculation sheets as presented in figures 4, 9 and 10. The accuracy of the results proves the applicability of the developed framework and its tools.

\section{Conclusion}

Exploiting the full potential of BIM, IPD and non-traditional cost estimation approaches, such as TVD, requires solutions that draw upon each approach's capabilities and advantages and benefit from the synergy of their combined use. With research in this field still in its infancy, this paper contributes in several ways. Firstly, the theoretical foundations and details of an innovative framework, along with analytical considerations for integrating these methodologies, are discussed in detail, extending the body of knowledge on the topic.

Secondly, the study moves one step ahead, progressing from promoting the integration of various solutions as proposed in previous studies, to providing a workable, practical solution based on the integration of Monte Carlo simulation, TVD and $\mathrm{ABC}$ with BIM-enabled integrated project delivery (IPD). This provides researchers with a sound foundation for exploring the potential for such integrative approaches and for investigating potential improvement.

As well as its research-focused contributions, the study's findings are also deemed invaluable for the world of practice, as discussed. Despite its contributions, this study is, in fact, a small part of an ongoing research project to develop an automated cost system for IPD projects based on BIM. Therefore, there is room and need for considerable further research in progress to develop this type of 


\section{This research is accepted to be published in ECAM journal DOI (10.1108/ECAM-04-2019-0222)}

project budgeting system. The focus for future studies must be on developing several proposals at the buyout stage to enable participants to make the right decision regarding acceptance or rejection of the offer. Moreover, proposing innovative ways for cost control using earned value management (EVM), preferably supported by a web system, is another area in which to extend the current study's findings. The chief limitation of this research concerns the use of different platforms to implement the proposed framework, thus exposing the study to issues of interoperability. However, in the current study, all the proposed platforms are interoperable, such as Revit, Navisworks and Excel. Future studies can overcome this by defining the development of Navisworks plug-ins to develop a costmanagement system within IPD, using the application programming interface (API), coded by C\#.NET.

Another limitation is that cost estimation in this research is about the expected cost; therefore, the market and allowable cost were not considered due to the need for application in a real-life case project. Moreover, the objective of the research was to prepare a detailed and continuous estimation technique for IPD, with the contingency and risk factors having been considered as part of the profitat-risk percentage without providing a detailed mechanism regarding the cost estimation of design contingencies. Even though the proposed BIM-based Monte Carlo Simulation tool can provide continuous cost estimation feedback, however, an automated tool is still needed to provide immediate cost estimation for any changes in the design to enable the designer to choose between different alternatives. All these limitations provide fertile grounds for research to improve the proposed framework and develop an automated cost management system for IPD projects using BIM. Additionally, the method used for this study focused on improving cost estimation prior to the construction stage, therefore, the variance between the two estimation methods was calculated based on planned values, rather than comparing with actual costs. Future studies on the topic can compare the outcome of estimation by the proposed solution against actual cost, to address this limitation.

\section{References}

AHMAD, I.AZHAR, N. and CHOWDHURY, A. (2019), "Enhancement of IPD Characteristics as Impelled by Information and Communication Technology". Journal of Management in Engineering, Vol. 35 No. 1. 04018055 .

AIA 2007. Integrated Project Delivery: A Guide. The American Institute of Architects. 


\section{This research is accepted to be published in ECAM journal DOI (10.1108/ECAM-04-2019-0222)}

AIBINU, A. and VENKATESH, S. (2013), "Status of BIM adoption and the BIM experience of cost consultants in Australia". Journal of Professional Issues in Engineering Education and Practice, Vol. 140 No. 3. 04013021.

ALASHWAL, A. M. and CHEW, M. Y. (2017), "Simulation techniques for cost management and performance in construction projects in Malaysia". Built Environment Project and Asset Management, Vol. 7 No. 5. 534-545.

ALLISON, M.ASHCRAFT, H.CHENG, R.KLAWANS, S. and PEASE, J. 2017. INTEGRATED PROJECT DELIVERY An Action Guide for Leaders [Online]. Lean Construction Institute. Available: https://www.leanconstruction.org/lci-news/integrated-project-delivery-an-action-guide-for-leaders/ [Accessed 20 December 2018].

ALVES, T. D. C. L.LICHTIG, W. and RYBKOWSKI, Z. K. (2017), "Implementing Target Value Design: Tools and Techniques to Manage the Process". HERD: Health Environments Research \& Design Journal, Vol. 10 No. 3. 18-29.

ALWISY, A.BOUFERGUENE, A. and AL-HUSSEIN, M. (2018), "Framework for target cost modelling in construction projects". International Journal of Construction Management. 1-16.

AMOS, S. J. 2004. Skills \& knowledge of cost engineering, AACE International Morgantown, WV.

ANDERSEN, B.SAMSET, K. and WELDE, M. (2016), "Low estimates - high stakes: underestimation of costs at the front-end of projects". International Journal of Managing Projects in Business, Vol. 9 No. 1. 171-193.

ASHCRAFT, H. W. (2014), "Integrated project delivery: a prescription for an ailing industry". Const. L. Int'l, Vol. 9. 21.

ASMAR, M. E.HANNA, A. S. and LOH, W.-Y. (2016), "Evaluating Integrated Project Delivery Using the Project Quarterback Rating". Journal of Construction Engineering and Management, Vol. 142 No. 1. 04015046.

AZHAR, N.KANG, Y. and AHMAD, I. (2015), "Critical Look into the Relationship between Information and Communication Technology and Integrated Project Delivery in Public Sector Construction". Journal of Management in Engineering, Vol. 31 No. 5. 04014091.

AZHAR, S.KHALFAN, M. and MAQSOOD, T. (2012), "Building information modelling (BIM): now and beyond". Construction Economics and Building, Vol. 12 No. 4. 15-28.

BALLARD, G.DILSWORTH, B.DO, D.LOW, W.MOBLEY, J.PHILLIPS, P.REED, D.SARGENT, Z.TILLMANN, P. and WOOD, N. How to Make Shared Risk and Reward Sustainable. In: SEPPÄNEN, O., GONZÁLEZ, V. A. \& ARROYO, P., eds. 23rd Annual Conference of the International Group for Lean Construction, 2015/07/29 2015 Perth, Australia. Perth, Australia, 257 266.

BERSSANETI, F. T. and CARVALHO, M. M. (2015), "Identification of variables that impact project success in Brazilian companies". International Journal of Project Management, Vol. 33 No. 3. 638-649.

BOON, J. and PRIGG, C. Evolution of quantity surveying practice in the use of BIM-the New Zealand experience. Proceedings of the CIB International Conference on Management and Innovation for a Sustainable Built Environment, 2012. 84-98.

CAFFIERI, J. J.LOVE, P. E.D.WHYTE, A. and AHIAGA-DAGBUI, D. D. (2018), "Planning for production in construction: controlling costs in major capital projects". Production Planning \& Control, Vol. 29 No. 1. 41-50.

CASSETTARI, L.MOSCA, M.MOSCA, R.ROLANDO, F.COSTA, M. and PISATURO, V. (2016), "IVF cycle cost estimation using Activity Based Costing and Monte Carlo simulation". Health care management science, Vol. 19 No. 1. 20-30.

CHANG, C.-Y.PAN, W. and HOWARD, R. (2017), "Impact of Building Information Modeling Implementation on the Acceptance of Integrated Delivery Systems: Structural Equation Modeling Analysis". Journal of Construction Engineering and Management, Vol. 143 No. 8. 04017044.

CHEN, G.ZHANG, G.XIE, Y.-M. and JIN, X.-H. (2012), "Overview of alliancing research and practice in the construction industry". Architectural Engineering and Design Management, Vol. 8 No. 2. 103-119.

CHO, D.RUSSELL, J. S. and CHOI, J. (2012), "Database framework for cost, schedule, and performance data integration". Journal of Computing in Civil Engineering, Vol. 27 No. 6. 719-731.

DAS, T. K. and TENG, B.-S. (2001), "Trust, Control, and Risk in Strategic Alliances: An Integrated Framework". Organization Studies, Vol. 22 No. 2. 251-283.

DE MELO, R. S. S.DO, D.TILLMANN, P.BALLARD, G. and GRANJA, A. D. (2016), "Target value design in the public sector: evidence from a hospital project in San Francisco, CA". Architectural Engineering and Design Management, Vol. 12 No. 2. 125-137.

DO, D.BALLARD, G. and TOMMELEIN, I. D. An analysis of potential misalignments of commercial incentives in Integrated Project Delivery and Target Value Design. Proceedings of the 23rd Conference of the International Group for Lean Construction, 2015. 277-286. 


\section{This research is accepted to be published in ECAM journal DOI (10.1108/ECAM-04-2019-0222)}

DO, D.CHEN, C.BALLARD, G. and TOMMELEIN, I. (2014), "Target value design as a method for controlling project cost overruns". International Group for Lean Construction, Vol. 22.

DOSSICK, C. S.AZARI, R.KIM, Y.-W. and EL-ANWAR, O. 2013. IPD in practice: Sustaining collaboration in healthcare design and construction. AEI 2013: Building Solutions for Architectural Engineering.

DURDYEV, S.HOSSEINI, M. R.MARTEK, I.ISMAIL, S. and ARASHPOUR, M. (2019), "Barriers to the use of integrated project delivery (IPD): a quantified model for Malaysia". Engineering, Construction and Architectural Management.

EASTMAN, C. M. A.LEE, G.SACKS, R. and TEICHOLZ, P. M. 2018. BIM handbook : a guide to building information modeling for owners, managers, designers, engineers and contractors, Hoboken, New Jersey Wiley.

EBRAHIMI, G. and DOWLATABADI, H. (2018), "Perceived Challenges in Implementing Integrated Project Delivery (IPD): Insights from Stakeholders in the U.S. and Canada for a Path Forward". International Journal of Construction Education and Research. 1-24.

ELGHAISH, F.ABRISHAMI, S.ABU SAMRA, S.GATERELL, M.HOSSEINI, M. R. and WISE, R. (2019a), "Cash flow system development framework within integrated project delivery (IPD) using BIM tools". International Journal of Construction Management. 1-16.

ELGHAISH, F.ABRISHAMI, S.HOSSEINI, M. R.ABU-SAMRA, S. and GATERELL, M. (2019b), "Integrated project delivery with BIM: An automated EVM-based approach". Automation in Construction, Vol. 106. 102907.

ELGHAISH, F. A. K.ABRISHAMI, S.HOSSEINI, M. R. and DEHKORDI, B. E. Integrating EVM and ABC for developing risk/rewards sharing metrics of IPD: A web-based management system. 36th CIB W78 2019 Conference, 2019c. International Council for Research and Innovation in Building and Construction, 831-841.

FAIRLEY, N.CARRICK, A. and FAIRLY, N. 2005. The casa cookbook, Acolyte science Cheshire.

FELLOWS, R. F. and LIU, A. M. 2015. Research methods for construction, John Wiley \& Sons.

FISCHER, M.KHANZODE, A.REED, D. and ASHCRAFT, H. W. 2017. Integrated Project Delivery, Somerset, US, John Wiley \& Sons.

GHASSEMI, R. and BECERIK-GERBER, B. (2011), "Transitioning to Integrated Project Delivery: Potential barriers and lessons learned". Lean construction journal, No. Lean and Integrated Project Delivery Special issue. 32-52.

HALL, D. M.ALGIERS, A. and LEVITT, R. E. (2018), "Identifying the Role of Supply Chain Integration Practices in the Adoption of Systemic Innovations". Journal of Management in Engineering, Vol. 34 No. 6. 04018030.

HANNON, J. J. (2007), "Estimators' functional role change with BIM". AACE International Transactions. IT31.

HOSSEINI, M. R.MAGHREBI, M.AKBARNEZHAD, A.MARTEK, I. and ARASHPOUR, M. (2018), "Analysis of Citation Networks in Building Information Modeling Research". Journal of Construction Engineering and Management, Vol. 144 No. 8. 04018064.

HUDSON-SMITH, A. (2014), "Tracking, tagging and scanning the city". Architectural Design, Vol. 84 No. 1. 40-47.

ILOZOR, B. D. and KELLY, D. J. (2012), "Building information modeling and integrated project delivery in the commercial construction industry: A conceptual study". Journal of Engineering, Project, and Production Management, Vol. 2 No. 1. 23-36.

JAHANGIRIAN, M.ELDABI, T.NASEER, A.STERGIOULAS, L. K. and YOUNG, T. (2010), "Simulation in manufacturing and business: A review". European Journal of Operational Research, Vol. 203 No. 1. $1-13$.

JANG, S.JEONG, Y.LEE, G. and KANG, Y. (2019), "Enhancing Subcontractors' Participation in BIM-Based - Design Coordination under a DBB Contract". Journal of Management in Engineering, Vol. 35 No. 6. 04019022.

JOHANSEN, A.SANDVIN, B.TORP, O. and ØKLAND, A. (2014), "Uncertainty analysis-5 challenges with today's practice". Procedia-Social and Behavioral Sciences, Vol. 119. 591-600.

KAHVANDI, Z.SAGHATFOROUSH, E.ALINEZHAD, M. and NOGHLI, F. (2017), "Integrated Project Delivery (IPD) Research Trends". Journal of Engineering, Project, and Production Management, Vol. 7 No. 2. 99-114.

KAHVANDI, Z.SAGHATFOROUSH, E.RAVASAN, A. Z. and MANSOURI, T. (2018), "An FCM-Based Dynamic Modelling of Integrated Project Delivery Implementation Challenges in Construction Projects". Lean Construction Journal. 63-87.

KHEDR, M. K. (2006), "Project risk management using Monte Carlo simulation". AACE International Transactions. RI21. 


\section{This research is accepted to be published in ECAM journal DOI (10.1108/ECAM-04-2019-0222)}

KIM, G.-H.AN, S.-H. and KANG, K.-I. (2004), "Comparison of construction cost estimating models based on regression analysis, neural networks, and case-based reasoning". Building and environment, Vol. 39 No. 10. 1235-1242.

KIM, Y.-W. and BALLARD, G. Activity-based costing and its application to lean construction. Proceedings of the 9th Annual Conference of the International Group for Lean Construction, Singapore, August, 2001 2001 National University of Singapore.

KIM, Y.-W.HAN, S.-H.YI, J.-S. and CHANG, S. (2016), "Supply chain cost model for prefabricated building material based on time-driven activity-based costing". Canadian Journal of Civil Engineering, Vol. 43 No. 4. 287-293.

KIM, Y. W.HAN, S.SHIN, S. and CHOI, K. (2011), "A case study of activity-based costing in allocating rebar fabrication costs to projects". Construction Management and Economics, Vol. 29 No. 5. 449-461.

KIVINIEMI, A.REKOLA, M.BELLONI, K.KOJIMA, J.KOPPINEN, T.MAKELAINEN, T. and HEITANEN, J. (2007), "Senate Properties: BIM Requirements 2007 Quantity Take-Off (Vol. 7)". Finland: Senate Properties.

LANCASTER, F. D. and TOBIN, J. Integrated project delivery: Next-generation BIM for structural engineering. Structures Congress 2010, 2010. 2809-2818.

LAURENT, J. and LEICHT, R. M. (2019), "Practices for Designing Cross-Functional Teams for Integrated Project Delivery". Journal of Construction Engineering and Management, Vol.145 No. 3. 05019001.

LI, D. W.JIN, F. and YIN, Y. New Method of Analyzing Cost Estimation by Integrating Monte-Carlo Simulation and Market Investigation. Abu Dhabi International Petroleum Exhibition and Conference, 2014. Society of Petroleum Engineers.

LOIZOU, P. and FRENCH, N. (2012), "Risk and uncertainty in development: A critical evaluation of using the Monte Carlo simulation method as a decision tool in real estate development projects". Journal of Property Investment \& Finance, Vol. 30 No. 2. 198-210.

LOVE, P. E.DAVIS, P. R.CHEVIS, R. and EDWARDS, D. J. (2011), "Risk/reward compensation model for civil engineering infrastructure alliance projects". Journal of Construction Engineering and Management, Vol. 137 No. 2. 127-136.

LU, Q.WON, J. and CHENG, J. C. P. (2016), "A financial decision making framework for construction projects based on 5D Building Information Modeling (BIM)". International Journal of Project Management, Vol. 34 No. 1. 3-21.

LU, W.LAI, C. C. and TSE, T. 2018. BIM and Big Data for Construction Cost Management, Milton, UNITED KINGDOM, Routledge.

MA, Z. and MA, J. (2017), "Formulating the application functional requirements of a BIM-based collaboration platform to support IPD projects". KSCE Journal of Civil Engineering, Vol. 21 No. 6. 2011-2026.

MANATA, B.MILLER, V.MOLLAOGLU, S. and GARCIA, A. J. (2018), "Measuring Key Communication Behaviors in Integrated Project Delivery Teams". Journal of Management in Engineering, Vol. 34 No. 4. 06018001.

MAYOUF, M.GERGES, M. and COX, S. (2019), "5D BIM: an investigation into the integration of quantity surveyors within the BIM process". Journal of Engineering, Design and Technology, Vol. 17 No. 3. 537-553.

MCCUEN, T. L.SUERMANN, P. C. and KROGULECKI, M. J. (2011), "Evaluating award-winning BIM projects using the national building information model standard capability maturity model". Journal of Management in Engineering, Vol. 28 No. 2. 224-230.

MEADATI, P.BIM extension into later stages of project life cycle. Associated Schools of Construction 45th Annual International Conference, 2009. 121-129.

MEIJON MORÊDA NETO, H.BASTOS COSTA, D. and COELHO RAVAZZANO, T. (2019), "Recommendations for Target Value Design implementation for real estate development in Brazil". Architectural Engineering and Design Management, Vol. 15 No. 1. 48-65.

MERSCHBROCK, C.HOSSEINI, M. R.MARTEK, I.ARASHPOUR, M. and MIGNONE, G. (2018), "Collaborative Role of Sociotechnical Components in BIM-Based Construction Networks in Two Hospitals". Journal of Management in Engineering, Vol. 34 No. 4. 05018006.

MESA, H. A.MOLENAAR, K. R. and ALARCÓN, L. F. (2016), "Exploring performance of the integrated project delivery process on complex building projects". International Journal of Project Management, Vol. 34 No. 7. 1089-1101.

NASSAR, K. (2011), "Assessing building information modeling estimating techniques using data from the classroom". Journal of Professional Issues in Engineering Education and Practice, Vol. 138 No. 3. $171-180$.

NASSAR, K. (2012), "Assessing Building Information Modeling Estimating Techniques Using Data from the Classroom". Journal of Professional Issues in Engineering Education and Practice, Vol. 138 No. 3. 171-180. 


\section{This research is accepted to be published in ECAM journal DOI (10.1108/ECAM-04-2019-0222)}

NGUYEN, P. and AKHAVIAN, R. (2019), "Synergistic Effect of Integrated Project Delivery, Lean Construction, and Building Information Modeling on Project Performance Measures: A Quantitative and Qualitative Analysis". Advances in Civil Engineering, Vol. 2019.

NIEMANN, R. 2017. IPD and BIM - the future of project delivery in Australia [Online]. McCullough Robertson. Available: http://www.mccullough.com.au/2017/10/05/ipd-bim-future-project-deliveryaustralia/ [Accessed 09 January 2018].

PISHDAD-BOZORGI, P. (2017), "Case Studies on the Role of Integrated Project Delivery (IPD) Approach on the Establishment and Promotion of Trust". International Journal of Construction Education and Research, Vol. 13 No. 2. 102-124.

PISHDAD-BOZORGI, P.MOGHADDAM, E. H. and KARASULU, Y. 2013. Advancing target price and target value design process in IPD using BIM and risk-sharing approaches. In: SULBARAN, T. (ed.) The 49th ASC Annual International Conference California Polytechnic State University: The Associated Schools of Construction.

PISHDAD-BOZORGI, P. and SRIVASTAVA, D. 2018. Assessment of Integrated Project Delivery (IPD) Risk and Reward Sharing Strategies from the Standpoint of Collaboration: A Game Theory Approach. Construction Research Congress 2018. New Orleans, Louisiana: American Society of CivilEngineers.

PMI 2017. A guide to the Project Management Body of Knowledge (PMBOK Guide), Newtown Square, Pennsylvania, Project Management Institute Standards Committee.

PORWAL, A. and HEWAGE, K. N. (2013), "Building Information Modeling (BIM) partnering framework for public construction projects". Automation in Construction, Vol. 31. 204-214.

POTTS, K. and ANKRAH, N. 2014. Construction Cost Management : Learning from Case Studies, Hoboken : Taylor and Francis, 2014. 2nd ed.

RAHIMIAN, F. P.IBRAHIM, R. and BAHARUDIN, M. N. Using IT/ICT as a new medium toward implementation of interactive architectural communication cultures. 2008 International Symposium on Information Technology, 2008. IEEE, 1-11.

RAHIMIAN, F. P.SEYEDZADEH, S.OLIVER, S.RODRIGUEZ, S. and DAWOOD, N. (2020), "On-demand monitoring of construction projects through a game-like hybrid application of BIM and machine learning". Automation in Construction, Vol. 110. 103012.

RAISBECK, P.MILLIE, R. and MAHER, A. (2010), "Assessing integrated project delivery: a comparative analysis of IPD and alliance contracting procurement routes". Management, Vol. 1019. 1028.

ROWLINSON, S. (2017), "Building information modelling, integrated project delivery and all that". Construction Innovation, Vol. 17 No. 1. 45-49.

ROY, D.MALSANE, S. and SAMANTA, P. K. (2018a), "Identification of Critical Challenges for Adoption of Integrated Project Delivery". Lean Construction Journal. 1-15.

ROY, D.MALSANE, S. and SAMANTA, P. K. 2018b. Identification of Critical Challenges for Adoption of Integrated Project Delivery. Lean Construction Journal [Online].

SHEN, Z. and ISSA, R. R. (2010), "Quantitative evaluation of the BIM-assisted construction detailed cost estimates".

SILVEIRA, S. and ALVES, T. (2018), "Target Value Design Inspired Practices to Deliver Sustainable Buildings". Buildings, Vol. 8 No. 9. 116.

STANLEY, R. and THURNELL, D. (2014a), "The benefits of, and barriers to, implementation of 5D BIM for quantity surveying in New Zealand". Construction Economics and Building, Vol. 14 No. 1. 105-117.

STANLEY, R. and THURNELL, D. (2014b), "The benefits of, and barriers to, implementation of 5D BIM for quantity surveying in New Zealand".

SUCCAR, B. (2009), "Building information modelling framework: A research and delivery foundation for industry stakeholders". Automation in construction, Vol. 18 No. 3. 357-375.

SUNIL, K.PATHIRAGE, C. and UNDERWOOD, J. Factors impacting Building Information Modelling (BIM) implementation in cost monitoring and control. 13th International Postgraduate Research Conference (IPGRC): conference proceedings, 2017. University of Salford, 210-224.

TILLMANN, P. A.DO, D. and BALLARD, G. A Case Study on the Success Factors of Target Value Design. 25th Annual Conference of the International Group for Lean Construction, 2017/07/09 2017 Heraklion, Greece. Heraklion, Greece, 563-570.

TORP, O. and KLAKEGG, O. J. (2016), "Challenges in Cost Estimation under Uncertainty-A Case Study of the Decommissioning of Barsebäck Nuclear Power Plant". Administrative Sciences, Vol. 6 No. 4. 14.

TRACH, R.POLONSKI, M. and HRYTSIUK, P. Modelling of Efficiency Evaluation of Traditional Project Delivery Methods and Integrated Project Delivery (IPD). IOP Conference Series: Materials Science and Engineering, 2019. IOP Publishing, 112043.

TSAI, W.-H.YANG, C.-H.CHANG, J.-C. and LEE, H.-L. (2014), "An Activity-Based Costing decision model for life cycle assessment in green building projects". European Journal of Operational Research, Vol. 238 No. 2. 607-619. 


\section{This research is accepted to be published in ECAM journal DOI (10.1108/ECAM-04-2019-0222)}

TSAI, W. H. and HUNG, S.-J. (2009), "A fuzzy goal programming approach for green supply chain optimisation under activity-based costing and performance evaluation with a value-chain structure". International Journal of Production Research, Vol. 47 No. 18. 4991-5017.

VIGNEAULT, M.-A.BOTON, C.CHONG, H.-Y. and COOPER-COOKE, B. (2019), "An innovative framework of 5D BIM solutions for construction cost management: A systematic review". Archives of Computational Methods in Engineering. 1-18.

WANG, P.DU, F.LEI, D. and LIN, T. W. (2010), "The choice of cost drivers in activity-based costing: Application at a Chinese oil well cementing company". International Journal of Management, Vol. 27 No. 2. 367.

WELDE, M. and ODECK, J. (2017), "Cost escalations in the front-end of projects - empirical evidence from Norwegian road projects". Transport Reviews, Vol. 37 No. 5. 612-630.

WU, S.WOOD, G.GINIGE, K. and JONG, S. W. (2014), "A technical review of BIM based cost estimating in UK quantity surveying practice, standards and tools". Journal of Information Technology in Construction (ITCon), Vol. 19. 534-562.

YIN, R. K. (1981), "The case study crisis: Some answers". Administrative Science Quarterly, Vol.26 No. 1. 58 65.

ZHANG, L. and LI, F. (2014), "Risk/reward compensation model for integrated project delivery". Engineering Economics, Vol. 25 No. 5. 558-567.

ZHANG, Y. and WANG, G. Cooperation between building information modeling and integrated project delivery method leads to paradigm shift of AEC industry. 2009 International Conference on Management and Service Science, 2009. IEEE, 1-4.

ZHENG, X.LU, Y.LI, Y.LE, Y. and XIAO, J. (2019), "Quantifying and visualizing value exchanges in building information modeling (BIM) projects". Automation in Construction, Vol. 99. 91-108.

ZHU, B.YU, L.-A. and GENG, Z.-Q. (2016), "Cost estimation method based on parallel Monte Carlo simulation and market investigation for engineering construction project".Cluster Computing, Vol. 19 No. 3. 1293-1308.

ZIMINA, D.BALLARD, G. and PASQUIRE, C. (2012), "Target value design: using collaboration and a lean approach to reduce construction cost". Construction Management and Economics, Vol. 30 No. 5. 383398. 